\title{
Performance of the Line-By-Line Radiative Transfer Model (LBLRTM) for temperature, water vapor, and trace gas retrievals: recent updates evaluated with IASI case studies
}

\author{
M. J. Alvarado ${ }^{1}$, V. H. Payne ${ }^{2}$, E. J. Mlawer ${ }^{1}$, G. Uymin ${ }^{1}$, M. W. Shephard ${ }^{3}$, K. E. Cady-Pereira ${ }^{1}$, J. S. Delamere ${ }^{1, *}$, \\ and J.-L. Moncet ${ }^{1}$ \\ ${ }^{1}$ Atmospheric and Environmental Research, Lexington, Massachusetts, USA \\ ${ }^{2}$ Jet Propulsion Laboratory, California Institute of Technology, Pasadena, California, USA \\ ${ }^{3}$ Environment Canada, Toronto, Ontario, Canada \\ *now at: Tech-X, Boulder, Colorado, USA
}

Correspondence to: M. J. Alvarado (malvarad@aer.com)

Received: 18 October 2012 - Published in Atmos. Chem. Phys. Discuss.: 4 January 2013

Revised: 16 April 2013 - Accepted: 10 June 2013 - Published: 15 July 2013

\begin{abstract}
Modern data assimilation algorithms depend on accurate infrared spectroscopy in order to make use of the information related to temperature, water vapor $\left(\mathrm{H}_{2} \mathrm{O}\right)$, and other trace gases provided by satellite observations. Reducing the uncertainties in our knowledge of spectroscopic line parameters and continuum absorption is thus important to improve the application of satellite data to weather forecasting. Here we present the results of a rigorous validation of spectroscopic updates to an advanced radiative transfer model, the Line-By-Line Radiative Transfer Model (LBLRTM), against a global dataset of 120 near-nadir, overocean, nighttime spectra from the Infrared Atmospheric Sounding Interferometer (IASI). We compare calculations from the latest version of LBLRTM (v12.1) to those from a previous version (v9.4+) to determine the impact of spectroscopic updates to the model on spectral residuals as well as retrieved temperature and $\mathrm{H}_{2} \mathrm{O}$ profiles. We show that the spectroscopy in the $\mathrm{CO}_{2} \nu_{2}$ and $\nu_{3}$ bands is significantly improved in LBLRTM v12.1 relative to v9.4+, and that these spectroscopic updates lead to mean changes of $\sim 0.5 \mathrm{~K}$ in the retrieved vertical temperature profiles between the surface and $10 \mathrm{hPa}$, with the sign of the change and the variability among cases depending on altitude. We also find that temperature retrievals using each of these two $\mathrm{CO}_{2}$ bands are remarkably consistent in LBLRTM v12.1, potentially allowing these bands to be used to retrieve atmospheric temperature simultaneously. The updated $\mathrm{H}_{2} \mathrm{O}$ spectroscopy in LBLRTM
\end{abstract}

v12.1 substantially improves the a posteriori residuals in the P-branch of the $\mathrm{H}_{2} \mathrm{O} \nu_{2}$ band, while the improvements in the R-branch are more modest. The $\mathrm{H}_{2} \mathrm{O}$ amounts retrieved with LBLRTM v12.1 are on average $14 \%$ lower between 100 and $200 \mathrm{hPa}, 42 \%$ higher near $562 \mathrm{hPa}$, and $31 \%$ higher near the surface compared to the amounts retrieved with v9.4+ due to a combination of the different retrieved temperature profiles and the updated $\mathrm{H}_{2} \mathrm{O}$ spectroscopy. We also find that the use of a fixed ratio of HDO to $\mathrm{H}_{2} \mathrm{O}$ in LBLRTM may be responsible for a significant fraction of the remaining bias in the P-branch relative to the R-branch of the $\mathrm{H}_{2} \mathrm{O} \nu_{2}$ band. There were no changes to $\mathrm{O}_{3}$ spectroscopy between the two model versions, and so both versions give positive a posteriori residuals of $\sim 0.3 \mathrm{~K}$ in the R-branch of the $\mathrm{O}_{3} \nu_{3}$ band. While the updates to the $\mathrm{H}_{2} \mathrm{O}$ self-continuum employed by LBLRTM v12.1 have clearly improved the match with observations near the $\mathrm{CO}_{2} \nu_{3}$ band head, we find that these updates have significantly degraded the match with observations in the fundamental band of CO. Finally, significant systematic a posteriori residuals remain in the $v_{4}$ band of $\mathrm{CH}_{4}$, but the magnitude of the positive bias in the retrieved mixing ratios is reduced in LBLRTM v12.1, suggesting that the updated spectroscopy could improve retrievals of $\mathrm{CH}_{4}$ from satellite observations. 


\section{Introduction}

Modern data assimilation algorithms for numerical weather prediction (NWP) make extensive use of the information related to temperature, water vapor $\left(\mathrm{H}_{2} \mathrm{O}\right)$, and other trace gases provided by satellite observations. The accuracy of the analyzed vertical profiles of temperature, $\mathrm{H}_{2} \mathrm{O}$, and other trace gases from satellites depends on the accuracy of the radiative transfer model used in the data assimilation. Uncertainties in our knowledge of spectroscopic line parameters and continua are the primary limitations on the accuracy of computed absorption in leading edge radiative transfer models, so reducing these uncertainties is an important part of improving the application of satellite data to weather forecasting. Radiance closure studies using high-spectralresolution infrared radiance measurements allow us to assess the systematic differences between the calculated and measured spectral radiances, and provide a means to assess the consistency of the input spectroscopic parameters within different absorption bands of the same trace gas (e.g., Shephard et al., 2009) and for different gaseous absorbers.

Here we present the results of a rigorous validation of spectroscopic updates to an advanced radiative transfer model, the Line-By-Line Radiative Transfer Model (LBLRTM, Clough et al., 1992, 2005), with respect to a dataset of measurements from the Infrared Atmospheric Sounding Interferometer (IASI, Challon et al., 2001), an infrared spectrometer on the EUMETSAT MetOp-A satellite launched in 2006. This study uses a global dataset of 120 clear-sky, nighttime, ocean, near-nadir IASI measurements during April 2008 culled from the dataset of Matricardi (2009), allowing the evaluation of the model across a large range of atmospheric conditions.

Section 2 describes the current and past versions of LBLRTM used in this study, and Sect. 3 provides an overview of the IASI instrument. Section 4 discusses our radiance closure strategy, including information on the a priori profiles, constraint matrices, and retrieval windows used in the retrievals of temperature, $\mathrm{H}_{2} \mathrm{O}, \mathrm{O}_{3}, \mathrm{CO}$, and $\mathrm{CH}_{4}$. Section 5 analyzes the results of these radiance closure studies and discusses the impact of the spectroscopic changes on retrieved profiles of temperature and $\mathrm{H}_{2} \mathrm{O}$.

\section{LBLRTM}

The Line-by-Line Radiative Transfer Model (LBLRTM) is an accurate and flexible radiative transfer model that can be used over the full spectral range from the microwave to the ultraviolet, providing the foundation for many radiative transfer applications (Clough et al., 1992, 2005). LBLRTM has a long and successful heritage at the leading edge of the field, and the model is continually updated and validated against high-resolution spectral measurements (e.g., Payne et al., 2008; Shephard et al., 2009; Delamere et al., 2010; Mlawer et al., 2012). LBLRTM calculations in the thermal infrared are recognized as a reference standard for intercomparisons of radiative transfer models, such as the SPARC Chemistry-Climate Model Validation Activity (CCMVal, Forster et al., 2011) and the Continual Intercomparison of Radiation Codes (CIRC, Oreopoulos and Mlawer, 2010; Oreopoulos et al., 2012).

LBLRTM has been widely used for a number of years as the foundation for retrieval algorithms, including those using measurements from ground-based instruments such as the Atmospheric Emitted Radiance Interferometer (AERI, Smith et al., 1999) and satellite instruments like IASI (Amato et al., 2002; Tjemkes et al., 2003) and the Tropospheric Emission Spectrometer (TES, Clough et al., 2006). In addition, LBLRTM has been used to derive the absorption coefficients for the fast radiation codes RRTM and RRTMG (Mlawer et al., 1997; Iacono et al., 2008), which are used for broadband flux and heating rate calculations in several general circulation models (GCMs) for climate and weather prediction. LBLRTM is also used to train fast radiative transfer models used in NWP assimilation systems, such as the Optical Path TRANsmittance model (OPTRAN; McMillin et al., 1979) and the Optimal Spectral Sampling (OSS) (Moncet et al., 2008) model implemented in the Joint Center for Satellite Data Assimilation (JCSDA) Community Radiative Transfer Model (CRTM), OPTRAN-Compact, which is used operationally at the National Centers for Environmental Prediction (NCEP), and the Radiative Transfer for TOVS (RRTOV) model (Matricardi et al., 2004; Matricardi, 2009) used by the EUMETSAT Satellite Application Facility on Numerical Weather Prediction.

The main features of LBLRTM are described in Clough et al. (2005) and are summarized here. The Voigt line shape is used at all atmospheric levels with an algorithm based on a linear combination of approximating functions. Line coupling in LBLRTM is modeled using a first-order perturbation approach (Rosenkranz, 1975). In general, errors associated with the computational procedures in LBLRTM are small around five times less than those associated with the limiting errors in spectral radiance calculations, which are uncertainties in line parameters and line shape. Spectroscopic parameters in the latest version of LBLRTM (v12.1) come from the HITRAN 2008 line database (Rothman et al., 2009) with a few key exceptions discussed in Sect. 2.2. LBLRTM incorporates the continuum model MT_CKD (Mlawer et al., 2012), which includes self- and foreign-broadened water vapor continua as well as continua for $\mathrm{CO}_{2}, \mathrm{O}_{2}, \mathrm{~N}_{2}, \mathrm{O}_{3}$, and extinction due to Rayleigh scattering. Temperature-dependent cross-section data such as those available with the HITRAN database may be used to treat the absorption due to heavy molecules such as halocarbons. The input cross-section data for all temperatures are at the lowest pressure available in HITRAN, and the pressure scaling of the cross section is then performed in LBLRTM by a convolution of the cross-section spectrum with an appropriate Lorentz function. 
In this work, we use two versions of LBLRTM. The first is a modified version of LBLRTM v9.4, here called v9.4+, which is described in Sect. 2.1. We chose v9.4+ for this study as this model version was released prior to the recent improvements in $\mathrm{CO}_{2}$ spectroscopy, including the addition of $\mathrm{P}$ - and $\mathrm{R}$-branch line coupling for all $\mathrm{CO}_{2}$ bands (Shephard et al., 2009). We compare the calculations from this older version of the model to those from the latest version, LBLRTM v12.1. The relevant updates made to LBLRTM, the MT_CKD continuum, and the associated spectral databases between v9.4 and v12.1 are discussed in Sect. 2.2.

\subsection{LBLRTM v9.4+}

LBLRTM v9.4 was released in January 2005. This version of the model used v1.0 of AER's line parameter database (hereafter AER v1.0), which was based on HITRAN 2000 (including all updates made before September 2001; see Rothman et al., 2003) with the following exceptions. All line parameters for $\mathrm{CH}_{4}$ between 922.65 and $1678.33 \mathrm{~cm}^{-1}$ and for the halfwidths, temperature dependence, and pressure shifts of $\mathrm{CO}$ were updated from HITRAN 2000 based on data supplied by Linda Brown of the Jet Propulsion Laboratory (personal communication, 2003). AER v1.0 also incorporated updated line parameters for $\mathrm{O}_{3}$ (Wagner et al., 2002), formic acid (HCOOH, Perrin et al., 1999) and for the A-bands of the minor isotopologues of $\mathrm{O}_{2}$ (Camy-Peyret et al., 2000); these three updates were later incorporated into HITRAN 2004 (Rothman et al., 2005).

Q-branch line coupling was included for $\mathrm{CO}_{2}$ in LBLRTM v9.4, but only for the main isotopologue. The first-order line coupling parameters in LBLRTM v9.4 for the Q-branches of the bands centered at $618,667,720,721$, and $791 \mathrm{~cm}^{-1}$ were based on Hoke et al. (1989), but were recalculated to be consistent with the $\mathrm{CO}_{2}$ line parameters in HITRAN 2000. The line coupling parameters for the Q-branches of the bands centered at 1932, 2076, 2093, and $2193 \mathrm{~cm}^{-1}$ were taken from Strow et al. (1994).

LBLRTM v9.4 used the continuum code MT_CKD v1.2. The formulation of the $\mathrm{H}_{2} \mathrm{O}$ self and foreign continua in MT_CKD is discussed in detail in Mlawer et al. (2012). The coefficients for the $\mathrm{CO}_{2}$ foreign continuum were based on Ridgway et al. (1982), with the coefficients between 0 and $1200 \mathrm{~cm}^{-1}$ increased by a factor of 7 to match AERI observations made at the U.S. Department of Energy (DoE) Atmospheric Radiation Measurement (ARM) program site at the North Slope of Alaska, as well as other observations made during the ARM//FIRE Water vapor Experiment (AFWEX) (Shephard et al., 2003). The continuum coefficients for the collision-induced fundamental bands of $\mathrm{O}_{2}$ and $\mathrm{N}_{2}$ were taken from Thibault et al. (1996) and Lafferty et al. (1996), respectively.

Several improvements to the functionality of LBLRTM were made between v9.4 and v12.1, most notably in the cal- culations of analytical Jacobians and the number of instrument line shapes included for post-processing the monochromatic spectra. In order to focus on differences between the versions due to spectroscopic parameters rather than these changes, we updated the fast Fourier transform (FFT) scan calculations and the analytical Jacobian calculations in LBLRTM v9.4 to match those of LBLRTM v12.1. This code, with spectroscopic parameters equivalent to v9.4 but with the improved features of LBLRTM v12.1, is here called LBLRTM v9.4+.

\subsection{LBLRTM v12.1}

LBLRTM v12.1 was released in November 2011. LBLRTM v12.1 uses v3.1 of the AER line parameter database (hereafter AER v3.1), which is based on the HITRAN 2008 line parameters (Rothman et al., 2009) with exceptions within the range of the IASI instrument for $\mathrm{H}_{2} \mathrm{O}, \mathrm{CO}_{2}$, and $\mathrm{CH}_{4}$, which are discussed below. The spectroscopic changes between AER v1.0 and AER v3.1 are negligible for CO and $\mathrm{O}_{3}$.

The $\mathrm{H}_{2} \mathrm{O}$ line positions and intensities for the range 10 to $2500 \mathrm{~cm}^{-1}$ in AER v3.1 are from Coudert et al. (2008). The Coudert et al. (2008) line list, as implemented in AER v3.1, included not only parameters for lines that they had measured in the laboratory (for wavenumbers up to $1750 \mathrm{~cm}^{-1}$ ) but also calculated values for lines that had not been measured, in order to provide a line list that would cover the entire range of the $\mathrm{H}_{2} \mathrm{O} v_{2}$ band in the thermal infrared. Note that while the Coudert et al. (2008) measured values were included in the HITRAN 2008 compilation, the HITRAN team had made the decision not to include the calculated values. The impacts of this difference between AER v3.1 and HITRAN 2008 are discussed in Sect. 5.2. The air-broadened half-widths, temperature dependences, and pressure shifts for $\mathrm{H}_{2} \mathrm{O}$ between 350 and $667 \mathrm{~cm}^{-1}$ are described in Delamere et al. (2010).

The $\mathrm{CO}_{2}$ line parameters in AER v3.1 were built by starting with the $\mathrm{CO}_{2}$ line mixing database of Lamouroux et al. (2010). This database takes most of its line positions, intensities, and lower state energies from the HITRAN 2008 database, but the values for air-broadened half-widths and their temperature dependence parameters are adjusted from the HITRAN 2008 values to be consistent throughout the bands, and the air-induced pressure shifts (not given for a majority of transitions in HITRAN 2008) were added. For AER v3.1, the $\mathrm{CO}_{2}$ line intensities and positions in the 597$2500 \mathrm{~cm}^{-1}$ spectral range were then modified to be consistent with the Carbon Dioxide Spectral Database (Tashkun et al., 1998, 2003) as implemented for MIPAS retrievals (Flaud et al., 2003). These line parameters were used to calculate first-order line coupling parameters for all lines of $\mathrm{CO}_{2}$ isotopologues 1 through 7 using the method and relaxations matrices of Lamouroux et al. (2010).

First-order line coupling parameters for the $v_{4}$ and $v_{3}$ bands of $\mathrm{CH}_{4}$ were calculated using HITRAN 2008 line 
parameters with the method and relaxation matrices of Tran et al. (2006).

LBLRTM v12.1 uses v2.5.2 of the MT_CKD continuum code, as described in detail by Mlawer et al. (2012). The selfbroadened continuum for $\mathrm{H}_{2} \mathrm{O}$ between 2000 and $3200 \mathrm{~cm}^{-1}$ is based on IASI, Atmospheric Infrared Sounder (AIRS), and AERI measurements between 2385 and $2600 \mathrm{~cm}^{-1}$, with the functional form for $2000-3200 \mathrm{~cm}^{-1}$ shaped by the nearIR studies of Bicknell et al. (2006) and Fulghum and Tilleman (1991). When P- and R-branch line coupling for $\mathrm{CO}_{2}$ was added to LBLRTM, the foreign broadened continuum of $\mathrm{CO}_{2}$ was completely recalculated under the impact approximation. In MT_CKD v2.5.2, empirical scaling factors, derived using IASI and AERI observations, were applied to these $\mathrm{CO}_{2}$ continuum coefficients between 2000 and $3000 \mathrm{~cm}^{-1}$ (Mlawer et al., 2012). The temperature dependence of the $\mathrm{CO}_{2}$ continuum between 2386 and $2434 \mathrm{~cm}^{-1}$ (due to the temperature dependence of the line mixing coefficients of the $\mathrm{CO}_{2}$ lines) was also accounted for in this version of the continuum (Mlawer et al., 2012). The coefficients for the collision-induced fundamental bands of $\mathrm{O}_{2}$ and $\mathrm{N}_{2}$ in MT_CKD 2.5.2 are the same as for MT_CKD v1.2 (see Sect. 2.1).

\section{IASI}

The Infrared Atmospheric Sounding Interferometer (IASI) instrument, which is on the European meteorological polar orbiting meteorological satellite MetOp-A, was designed for (1) operational meteorological soundings (e.g., of temperature and $\mathrm{H}_{2} \mathrm{O}$ ) with the goal of improving medium-range weather forecasts and (2) studying atmospheric chemistry, with the goal of measuring and monitoring trace gases such as $\mathrm{O}_{3}, \mathrm{CO}$, and $\mathrm{CH}_{4}$ on a global scale. IASI is an accurately calibrated Fourier transform spectrometer operating in the $645-2760 \mathrm{~cm}^{-1}(15.5-3.6 \mu \mathrm{m})$ spectral range with $0.5 \mathrm{~cm}^{-1}$ (apodized) resolution (Challon et al., 2001). Instrument characteristics are as described in Shephard et al. (2009). The IASI instrument line shape is modeled as a truncated Gaussian with a 1/e point (i.e., the spectral distance from the channel center at which the Gaussian equals 1/e times its maximum value) at $0.25 \mathrm{~cm}^{-1}$. The calibration and validation of the IASI Level 1 radiances is described in Blumstein et al. (2007). The assessment of the in-flight performance has shown remarkably good radiometric performance (noise characteristics are similar to those measured on the ground) and excellent absolute calibration (better than $0.1 \mathrm{~K}$ ). The spectral calibration was also shown to be remarkable (mean relative error on spectral calibration of $3.1 \pm 3.3 \times 10^{-7}$; Blumstein et al., 2007).

Here we use a set of 120 near-nadir (i.e., off-nadir angle less than $17.75^{\circ}$ ) spectra measured by IASI in April 2008, which are a subset of the profiles analyzed by Matricardi (2009). Only clear sky (i.e., cases that passed the ECMWF cloud detection algorithm of McNally and Watts (2003), and thus for which the impact of clouds on brightness temperatures is less than $\sim 0.2 \mathrm{~K}$ ), ocean, nighttime cases were selected in order to minimize uncertainties associated with cloud, surface emissivity and non-local thermodynamic equilibrium (non-LTE) effects. This left 130 profiles, 9 of which failed to converge for one or more of the retrievals discussed in Sect. 4 below, and 1 of which showed clearly biased residuals in the $\mathrm{H}_{2} \mathrm{O} \nu_{2}$ and $\mathrm{CO}_{2} \nu_{3}$ band after convergence, leaving us with a set of 120 cases for analysis. These 120 profiles cover a wide range of surface temperatures and precipitable water vapor amounts. Table 1 shows the number of spectra with precipitable water vapor (PWV) between $0-2,2-4$, and 4-6 cm, along with the corresponding ranges of surface temperature $\left(T_{\text {srf }}\right)$ and latitude.

\section{Radiance closure method}

The validation of the molecular spectroscopy in a radiative transfer model like LBLRTM with observed spectral radiances from satellite- and ground-based sensors, as in Shephard et al. (2009) and this study, requires a careful consideration of the dominant uncertainties in the input parameters of the model. For the cloudless, nighttime, over-ocean cases considered in this paper, the dominant sources of uncertainty in the model inputs are (1) errors in the specification of the atmospheric state, i.e., the vertical profiles of temperature and trace gases for each case; and (2) errors in the spectroscopic line parameters and continua. In general, errors in the specification of the atmospheric state are unavoidable - either in situ profile measurements are unavailable, or the in situ measurements have significant uncertainties, or the in situ measurements did not sample the atmosphere at the exact same space and time as the satellite observation. For example, the comparisons of radiosondes launched from the ARM Southern Great Plains site an hour apart showed significant variability in temperature $(0.5-1 \mathrm{~K}$ over $1 \mathrm{~km}$ averaged layers) and water vapor $(25 \%$ for $2 \mathrm{~km}$ thick layers, Tobin et al., 2006). Model profiles, with their finite temporal and spatial resolution, present similar issues.

We thus chose to use retrievals of temperature and trace gases to adjust optimally our specification of the atmospheric state prior to analysis of the spectral residuals, as done in Shephard et al. (2009). Using the observed spectra to provide an optimal estimate of the atmospheric state can reduce the impact of collocation errors and any systematic in situ observation or model biases on the residuals, allowing the systematic issues in the spectroscopy to be more easily discerned. Thus, we first minimize the errors in the specification of the atmospheric state by using each of the two versions of LBLRTM discussed in Sect. 2 to retrieve best-fit specifications of the atmospheric state for all cases in the dataset. However, we also present the mean a priori residuals for each 
Table 1. Number of IASI spectra in each range of precipitable water vapor $(\mathrm{PWV})$, and the associated surface temperature $\left(T_{\mathrm{srf}}\right)$ and latitude range.

\begin{tabular}{llll}
\hline PWV $(\mathrm{cm})$ & $\begin{array}{l}\text { Number } \\
\text { of Spectra }\end{array}$ & $T_{\text {srf }}$ Range $(\mathrm{K})$ & Latitude Range \\
\hline $0-2$ & 33 & $271-300$ & $59^{\circ} \mathrm{S}$ to $21^{\circ} \mathrm{S}$, \\
& & $28^{\circ} \mathrm{N}$ to $62^{\circ} \mathrm{N}$ \\
$2-4$ & 57 & $293-303$ & $35^{\circ} \mathrm{S}$ to $28^{\circ} \mathrm{N}$ \\
$4-6$ & 30 & $298-303$ & $25^{\circ} \mathrm{S}$ to $21^{\circ} \mathrm{N}$ \\
\hline
\end{tabular}

model version along side the final a posteriori residuals in our analysis (see Sect. 5).

We use an optimal estimation retrieval approach to minimize the difference between the observed IASI spectral radiances and corresponding LBLRTM calculations subject to the constraint that the estimated atmospheric state must be consistent with an a priori probability distribution for that state (Bowman et al., 2006; Clough et al., 1995; Rodgers, 2000). Specifically, we retrieve the following parameters: the surface or "skin" temperature $T_{\text {sff }}$; the vertical profile of temperature $T_{\text {atm }}$; and the vertical profiles of water vapor $\left(\mathrm{H}_{2} \mathrm{O}\right)$, ozone $\left(\mathrm{O}_{3}\right)$, carbon monoxide $(\mathrm{CO})$, and methane $\left(\mathrm{CH}_{4}\right)$.

Our retrieval procedure is shown schematically in Fig. 1. We start with an a priori specification of the atmospheric state for each IASI spectrum. This a priori specification was constructed as follows. $T_{\text {srf }}$ (and the surface pressure) is taken from the output of version 33R1 of the ECMWF model as discussed in Matricardi (2009). The a priori profile for $T_{\text {atm }}$ at altitudes below the $10 \mathrm{hPa}$ surface and altitudes above the $0.1 \mathrm{hPa}$ surface is taken from the same ECMWF model output. However, the work of Masiello et al. (2011) showed that ECMWF temperature profiles overestimate the true atmospheric temperature by up to $12 \mathrm{~K}$ between $10 \mathrm{hPa}$ and $0.1 \mathrm{hPa}$, leading to significant errors in the radiances near the $667 \mathrm{~cm}^{-1} \mathrm{Q}$-branch of $\mathrm{CO}_{2}$. Thus, in this region we apply a correction to the ECMWF temperature profile. The correction peaks at $-12 \mathrm{~K}$ at $0.3 \mathrm{hPa}$, and is linearly interpolated in the natural logarithm of pressure between this point and the $0 \mathrm{~K}$ correction values at $10 \mathrm{hPa}$ and $0.1 \mathrm{hPa}$.

The a priori profile for $\mathrm{H}_{2} \mathrm{O}$ is also taken from the ECMWF model output as discussed in Matricardi (2009). For $\mathrm{O}_{3}$, these ECMWF model profiles were scaled to match the total column of $\mathrm{O}_{3}$ as observed by the Ozone Monitoring Instrument (OMI). For $\mathrm{CO}_{2}, \mathrm{~N}_{2} \mathrm{O}, \mathrm{CH}_{4}$, and $\mathrm{CO}$, the a priori profiles are from the NASA Aura TES monthly climatology for April 2008, which is based on the MOZART global chemical transport model (Brasseur et al., 1998). For all the retrievals discussed below, the a priori profile is also the initial guess profile for the retrievals. Fixed, best estimate profiles for $\mathrm{HCOOH}$ and $\mathrm{C}_{2} \mathrm{H}_{4}$ are from the climatologies developed for the NASA Upper Atmospheric Research Satellite (UARS, A. Goldman, personal communication, 2002). For

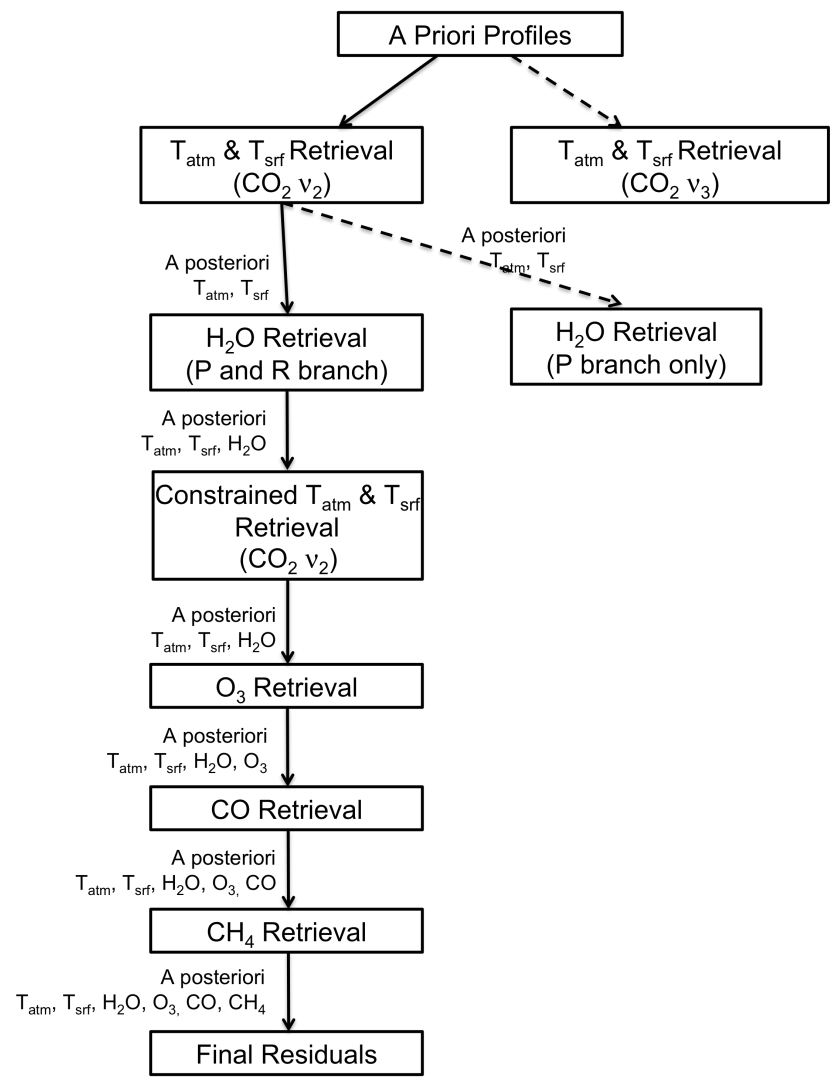

Fig. 1. Schematic of the retrieval procedure used in this study. Solid arrows show the main line from the a priori profiles described in Sect. 4 to the final residuals for the two models (LBLRTM v12.1 and LBLRTM v9.4+). The dashed lines show additional retrievals done to assess the consistency of the spectroscopy between the $v_{2}$ and $v_{3}$ bands of $\mathrm{CO}_{2}$ and the P- and R-branches of $\mathrm{H}_{2} \mathrm{O}$.

$\mathrm{CCl}_{4}, \mathrm{CFC}-11, \mathrm{CFC}-12$, and $\mathrm{CHClF}_{2}$, the (vertically wellmixed) fixed, best estimate profiles are the UARS profiles scaled to match the April 2008 global average mixing ratios as reported by the NOAA/ESRL Global Monitoring Division (91.3 ppt, $245.4 \mathrm{ppt}, 535.7 \mathrm{ppt}$, and $190.1 \mathrm{ppt}$, respectively; available at ftp://ftp.cmdl.noaa.gov/hats/cfcs/). The $\mathrm{CF}_{4}$ best estimate profile is the UARS profile scaled to match the latest available observations (74 ppt in 1997; Khalil et al., 2003; Forster et al., 2007). Fixed, best estimate profiles for all other trace gases considered in this study (i.e., $\mathrm{SO}_{2}, \mathrm{NH}_{3}, \mathrm{HNO}_{3}$, OCS, HCN, and $\mathrm{C}_{2} \mathrm{H}_{2}$ ) were taken from the US Standard Atmosphere (NOAA, 1976). A fixed, best estimate spectral surface emissivity was estimated from the Wu and Smith (1997) model (zero wind speed, zero viewing angle) as described in van Delst and Wu (2000).

Starting with these a priori profiles, we performed the following retrievals for each IASI spectrum and version of LBLRTM. First, we performed two combined retrievals of $T_{\text {srf }}$ and $T_{\text {atm }}$, as shown in Fig. 1. (Note that surface pressure was not retrieved, and was instead left at the ECMWF value.) 
Table 2. List of spectral regions used in the retrievals.

\begin{tabular}{ll}
\hline Retrieved Parameter & Spectral regions used in retrievals $\left[\mathrm{cm}^{-1}\right]$ \\
\hline$T_{\text {srf }}$ & $817.0-823.0,831.0-834.5,843.0-848.0,960.0-965.0,1088.0-1090.0,1144.0-$ \\
& $1146.0,1231.5-1232.50,1330.25-1330.75,2001.5-2005.0,2011.5-2013.25$, \\
& $2030.0-2032.0,2499.0-2501.0,2604.0-2606.0$ \\
\hline$T_{\text {atm }}\left(\mathrm{CO}_{2} v_{2}\right.$ band $)$ & $650.0-780.0$ \\
\hline$T_{\text {atm }}\left(\mathrm{CO}_{2} v_{3}\right.$ band $)$ & $2270.0-2499.0$ \\
\hline $\mathrm{H}_{2} \mathrm{O}$ & $1164.5-1166.25,1173.0-1175.5,1186.0-1188.0,1197.0-1199.0,1210.75-$ \\
& $1213.25,1224.25-1226.25,1242.5-1245.25,1257.75-1261.75,1375.0-$ \\
& $1560.0,1640.0-2020.0$ \\
\hline $\mathrm{O}_{3}$ & $990.0-1070.0$ \\
\hline $\mathrm{CO}$ & $2072.75-2074.0,2094.0-2095.50,2098.0-2099.75,2102.25-2104.25$, \\
& $2110.25-2112.50,2118.75-2120.50,2127.0-2135.0,2149.5-2151.75$, \\
& $2153.50-2155.50,2157.25-2159.50,2164.75-2177.0,2179.0-2180.50$, \\
\hline $\mathrm{CH}_{4}$ & $2182.5-2184.0,2186.0-2187.5,2189.25-2190.75,2192.75-2194.25$ \\
\hline
\end{tabular}

These retrievals use different spectral regions to provide information on $T_{\mathrm{atm}}$ - in the first, the $\nu_{2}$ band of $\mathrm{CO}_{2}$ is used, while in the second the $v_{3}$ band of $\mathrm{CO}_{2}$ is used. (Example averaging kernels for these and the other retrievals in this work are included in the Supplement, which also shows the pressure levels included in the state vector for each retrieval.) The profiles of $T_{\text {atm }}$ retrieved using these two different spectral ranges are compared in Sect. 5.1 below in order to evaluate the consistency of the spectroscopy for the two $\mathrm{CO}_{2}$ bands in both versions of LBLRTM. The set of spectral ranges or "retrieval windows" primarily sensitive to $T_{\text {srf }}$ are the same in both of these retrievals - these ranges (and the spectral ranges used to retrieve all other parameters) are given in Table 2 . In general, following our emphasis on evaluating the consistency of the spectroscopy within and between bands, we have opted to use large spectral regions in our retrievals. We recognize, however, that our results can only be suggestive of the impacts on operational assimilation and retrieval schemes (which generally use only a small subset of the available channels), and that the impact of the updated spectroscopy in LBLRTM v12.1 on any specific retrieval or assimilation method would have to be carefully evaluated on its own in future work.

The associated covariance matrix for $T_{\text {srf }}$ and $T_{\text {atm }}$ was constructed as follows. First, $T_{\text {srf }}$ was assumed to have a standard deviation of $1 \mathrm{~K}$. For $T_{\mathrm{atm}}$, the diagonal of the covariance matrix was set by assuming that the a priori probability distribution of $T_{\text {atm }}$ had a standard deviation of $2 \mathrm{~K}$ between the surface at $200 \mathrm{hPa}, 4 \mathrm{~K}$ between $200 \mathrm{hPa}$ and $50 \mathrm{hPa}, 7 \mathrm{~K}$ between 50 and $10 \mathrm{hPa}$, and $10 \mathrm{~K}$ above $10 \mathrm{hPa}$. This gradually increasing uncertainty in the a priori of $T_{\mathrm{atm}}$ with altitude was chosen to avoid overconstraining the upper atmospheric temperatures, as the values in our corrected a priori profile above $10 \mathrm{hPa}$ must be considered highly uncertain. We then assumed a Gaussian correlation length of $1 \mathrm{~km}$ between the retrieved levels in order to account for the correlations between the different retrieval levels (the off-diagonal elements of the covariance matrix). No a priori correlation was assumed between $T_{\text {srf }}$ and the lowest levels of the $T_{\text {atm }}$ profile.

Next, we used the a posteriori values for $T_{\text {srf }}$ and $T_{\text {atm }}$ from the $\mathrm{CO}_{2} v_{2}$ band temperature retrieval as inputs into two retrievals of $\mathrm{H}_{2} \mathrm{O}$ (see Fig. 1; note that, for all gases, the parameter retrieved was the natural $\log$ of the volume mixing ratio). In the first $\mathrm{H}_{2} \mathrm{O}$ retrieval, hereafter referred to as the "Pand R-branch retrieval", all of the retrieval windows given for $\mathrm{H}_{2} \mathrm{O}$ in Table 2 are used. In the second retrieval, hereafter the "P-branch retrieval", the range covering the R-branch of the $v_{2}$ band of $\mathrm{H}_{2} \mathrm{O}$ (i.e., $1640-2020 \mathrm{~cm}^{-1}$ ) was excluded in order to investigate the impact on water vapor retrievals when only the P-branch is observed, as is the case for the Atmospheric Infrared Sounder (AIRS) and the Cross-track Infrared Sounder (CrIS) satellite instruments (see Sect. 5.2 below). The a priori covariance of $\mathrm{H}_{2} \mathrm{O}$ was assumed to have an uncertainty of $20 \%$ at all levels with off-diagonal correlation lengths of $1 \mathrm{~km}$.

The a posteriori profiles of $T_{\text {srf }}, T_{\mathrm{atm}}$, and $\mathrm{H}_{2} \mathrm{O}$ from the $\mathrm{P}$ - and R-branch retrieval of $\mathrm{H}_{2} \mathrm{O}$ were then used as input to a more highly constrained retrieval of $T_{\text {srf }}$ and $T_{\text {atm }}$. This additional retrieval step is required to minimize the impacts of errors in the atmospheric state on the final spectral residuals, as the temperatures retrieved using the a priori $\mathrm{H}_{2} \mathrm{O}$ profile can be somewhat different than the temperatures retrieved using the a posteriori $\mathrm{H}_{2} \mathrm{O}$ profile. In this step, both $T_{\text {atm }}$ and $T_{\text {srf }}$ were assumed to have standard deviations of $1 \mathrm{~K}$ at all heights, and the off-diagonal elements for $T_{\mathrm{atm}}$ a 
priori covariance matrix were again calculated using a $1 \mathrm{~km}$ correlation length.

These improved a posteriori profiles of $T_{\text {srf }}$ and $T_{\text {atm }}$, along with the $\mathrm{H}_{2} \mathrm{O}$ profiles from the $\mathrm{P}$ - and $\mathrm{R}$-branch retrieval, were then used as input to sequential retrievals of $\mathrm{O}_{3}, \mathrm{CO}$, and $\mathrm{CH}_{4}$ to produce our final estimate of the atmospheric state and thus our final set of spectral residuals (see Fig. 1; note that all a posteriori residual plots in this paper are from this final set of residuals after all parameters have been retrieved). The a priori covariance matrices of $\mathrm{O}_{3}, \mathrm{CO}$, and $\mathrm{CH}_{4}$ were generated assuming uncertainties of $20 \%, 20 \%$, and $5 \%$ at all levels and off-diagonal correlation lengths of $1 \mathrm{~km}, 2 \mathrm{~km}$, and $1 \mathrm{~km}$, respectively.

\section{Results and discussion}

Figure 2 shows the mean residuals for the 120 scans across the IASI spectral range using LBLRTM v12.1 and LBLRTM v9.4+, along with an example observed spectrum for a profile with $1.5 \mathrm{~cm}$ PWV. The figures also display the mean and root mean square (RMS) of the residuals for each model across the IASI spectral range. Note that the RMS is the RMS of the mean residuals plotted in the figure:

RMS $=\sqrt{\frac{\sum_{i=1, N_{\text {channels }}}\left(\frac{\sum_{j=1, N_{\text {scans }}} \mathrm{Obs}_{i, j}-\mathrm{Model}_{i, j}}{N_{\text {scans }}}\right)^{2}}{N_{\text {channels }}}}$,

where $\mathrm{Obs}_{i, j}$ is the IASI-observed radiance (or brightness temperature) in spectral channel $i$ for scan $j, \operatorname{Model}_{i, j}$ the corresponding LBLRTM-simulated radiance or brightness temperature, and $N_{\text {scans }}$ and $N_{\text {channels }}$ the number of scans and spectral channels included in the average, respectively. The RMS is generally the correct metric to use when evaluating the spectral residuals, as (a) the RMS includes contributions from both the mean bias and the standard deviation about that mean, and (b) the retrievals explicitly minimize the mean bias averaged over all channels in the retrieval windows. However, comparing the mean bias in different spectral regions used in the same retrieval (as in the evaluation of the $\mathrm{H}_{2} \mathrm{O}$ spectroscopy in Sect. 5.2) can be a useful indicator of inconsistent spectroscopy within a band, and is thus also presented.

Figure 2 shows that the RMS of the mean residuals across the IASI spectrum in LBLRTM v12.1 are generally lower than in LBLRTM v9.4+, both in the mean residuals after the retrieval procedure (i.e., the final a posteriori residuals in $2 \mathrm{~b}$ and $2 \mathrm{c}$ ) and in the a priori mean residuals ( $2 \mathrm{~d}$ and $2 \mathrm{e}$ ). However, significant systematic spectral residuals remain in LBLRTM v12.1. In the following sections, we discuss the changes in the spectral residuals in several spectral regions within the IASI spectral range, along with the associated impact on the retrievals on atmospheric profiles of temperature, $\mathrm{H}_{2} \mathrm{O}, \mathrm{O}_{3}, \mathrm{CO}$, and $\mathrm{CH}_{4}$.
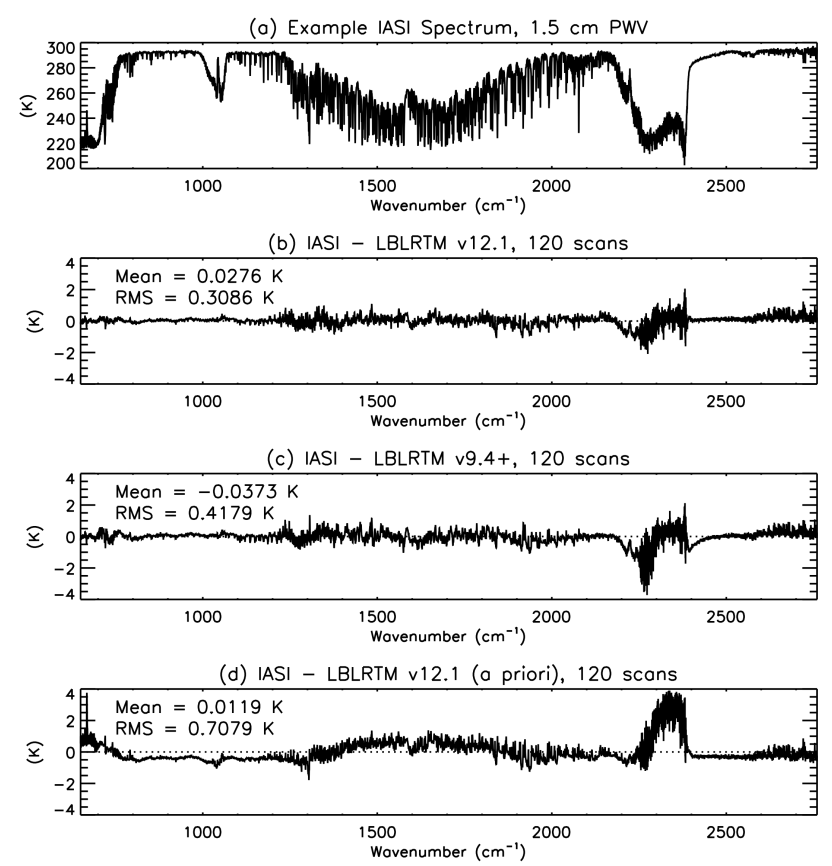

(e) IASI - LBLRTM v9.4+ (a priori), 120 scans

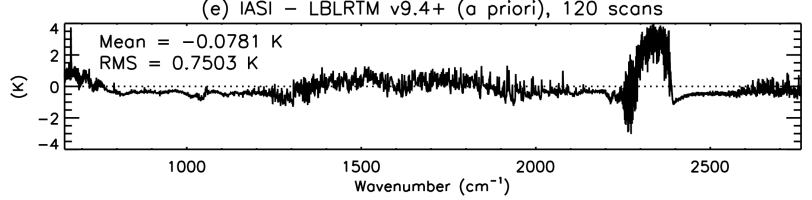

Fig. 2. (a) IASI-observed brightness temperature spectrum for an example profile with $1.5 \mathrm{~cm}$ PWV. (b) Mean of the final (a posteriori) brightness temperature residuals for 120 spectra using LBLRTM v12.1. (c) Mean of the final brightness temperature residuals for 120 spectra using LBLRTM v9.4+. (d) Mean of the a priori brightness temperature residuals for 120 spectra using LBLRTM v12.1. (e) Mean of the final brightness temperature residuals for 120 spectra using LBLRTM v9.4+. Note that the RMS due to instrument noise alone is $0.17 \mathrm{~K}$.

\section{$5.1 \mathrm{CO}_{2} v_{2}\left(640-800 \mathrm{~cm}^{-1}\right)$ and $v_{3}\left(2200-2550 \mathrm{~cm}^{-1}\right)$ bands}

Figure 3 shows the mean of the final brightness temperature residuals in the $\mathrm{CO}_{2} \nu_{2}$ band for all 120 IASI scans considered here for both LBLRTM v12.1 (Fig. 3b) and v9.4+ (Fig. 3c). The mean a priori residuals for each model are presented in Fig. 3d and e. (Errors in these mean residuals from IASI instrument noise are generally too small to be seen on the same scale as the residuals. The interested reader will find plots of the expected error in the 120 case mean residuals from IASI noise in the Supplement.) The $\mathrm{CO}_{2} v_{2}$ band atmospheric temperature retrieval window is shown in red, along with the mean and RMS of the residuals within this window.

The updated $\mathrm{CO}_{2}$ spectroscopy in LBLRTM v12.1 clearly improves the residuals on either side of the $\mathrm{CO}_{2}$ Q-branch at $720 \mathrm{~cm}^{-1}$. The RMS of the final a posteriori residuals in 


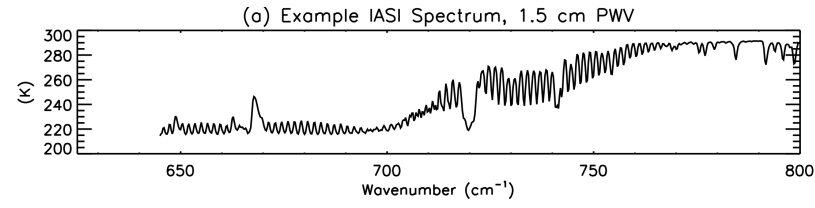

(b) IASI - LBLRTM V12.1, 120 scans

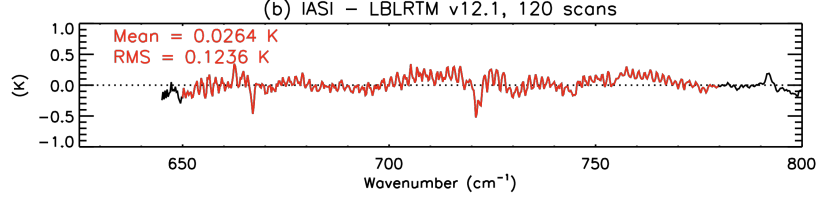

(c) IASI - LBLRTM v9.4+, 120 scons

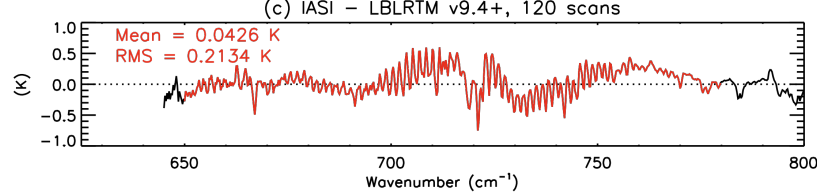

(d) IASI - LBLRTM v12.1 (a priori), 120 scans

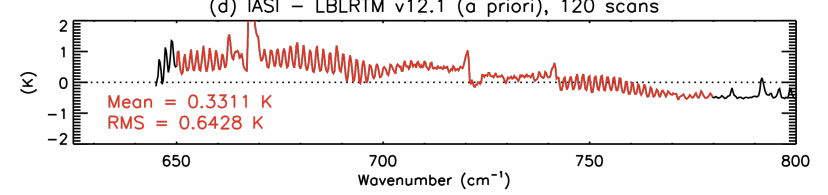

(e) IASI - LBLRTM v9.4+ (o priori), 120 scans

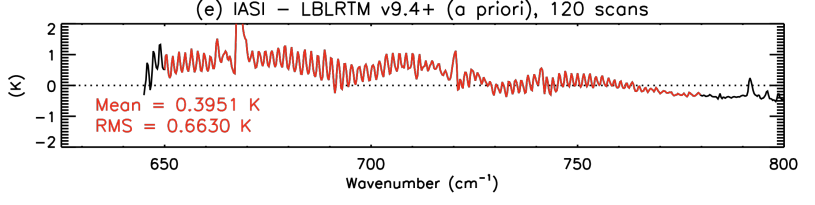

Fig. 3. (a) IASI-observed brightness temperature spectrum in the $v_{2}$ band of $\mathrm{CO}_{2}$ for an example profile with $1.5 \mathrm{~cm}$ PWV. (b) Mean of the final (a posteriori) brightness temperature residuals for 120 spectra using LBLRTM v12.1. (c) Mean of the final brightness temperature residuals for 120 spectra using LBLRTM v9.4+. (d) Mean of the a priori brightness temperature residuals for 120 spectra using LBLRTM v12.1. (e) Mean of the a priori brightness temperature residuals for 120 spectra using LBLRTM v9.4+. A priori residuals in the $667 \mathrm{~cm}^{-1} \mathrm{Q}$-branch peak at approximately $4 \mathrm{~K}$. The $v_{2}$ retrieval window (which was used to retrieve $T_{\text {atm }}$ and $T_{\text {srf }}$ ) is highlighted in red. Note that the RMS due to instrument noise alone in this retrieval window is $0.045 \mathrm{~K}$.

the $v_{2}$ retrieval window shows substantial improvement in LBLRTM v12.1 $(0.12 \mathrm{~K})$ versus v9.4+ $(0.21 \mathrm{~K})$. The a priori residuals also have a lower RMS in v12.1. The major remaining a posteriori residual features in LBLRTM v12.1 are negative residuals of $\sim 0.5 \mathrm{~K}$ in the 667 and $720 \mathrm{~cm}^{-1}$ Q-branches and a positive offset of $\sim 0.2 \mathrm{~K}$ between 755 and $770 \mathrm{~cm}^{-1}$.

This improvement in the residuals is primarily from the addition of P- and R-branch line coupling to LBLRTM (and the associated recalculation of the $\mathrm{CO}_{2}$ continuum in MT_CKD), as shown in Fig. 4. Figure 4 compares the modeled spectrum between LBLRTM simulations using the $\mathrm{CO}_{2}$ line parameters from LBLRTM v9.4+, v11.1 (HITRAN 2004 with P-, Q-, and R-branch line coupling from Niro et al., 2005), the Lamouroux et al. (2010) line coupling database (HITRAN 2008 with P-, Q-, and R-branch line coupling, but without the CDSD position and strength changes
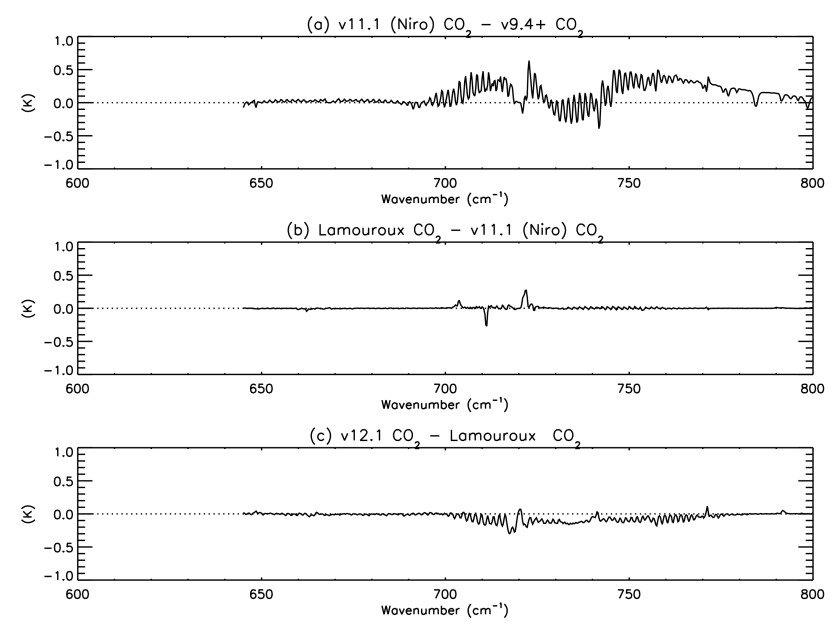

Fig. 4. Differences of the modeled brightness temperature spectrum (moderate water vapor case) in the $\mathrm{CO}_{2} v_{2}$ band due to changes in $\mathrm{CO}_{2}$ spectroscopy. All results are for the moderate water vapor case. (a) LBLRTM v11.1 CO $\mathrm{CO}_{2}$ (which includes the Niro et al. (2005) P-, Q-, and R-branch line coupling parameters) minus v9.4+. (b) Lamouroux et al. (2010) line coupling parameters (based on HITRAN 2008) minus Niro et al. (2005) (based on HITRAN 2004). (c) v12.1 $\mathrm{CO}_{2}$ parameters (with CDSD position and strengths) minus Lamouroux et al. (2010).

of Tashkun et al., 2003), and v12.1 for our moderate water vapor case. It is obvious that the biggest changes between the versions came with the introduction of $\mathrm{P}$ - and $\mathrm{R}$-branch line coupling, with relatively smaller impacts from the use of the CDSD positions and strengths, and the differences between the Niro et al. (2005) and Lamouroux et al. (2010) line parameters are negligible except for a few key regions between 700 and $730 \mathrm{~cm}^{-1}$.

Figures 5 and 6 show the mean a posteriori residuals binned by PWV for LBLRTM v12.1 and LBLRTM v9.4+, respectively. The residual feature at the $667 \mathrm{~cm}^{-1}$ Q-branch appears to be independent of PWV, while the residuals in the $720 \mathrm{~cm}^{-1}$ Q-branch and between 755 and $770 \mathrm{~cm}^{-1}$ both appear to increase with increasing amounts of water vapor. The RMS of the residuals in the $v_{2}$ retrieval window also appears to increase with PWV in both models. However, since PWV is well correlated with atmospheric temperature and latitude (see Table 1), the apparent dependence of the $720 \mathrm{~cm}^{-1}$ Q-branch residuals on PWV may actually be due to the dependence on the atmospheric temperature structure (e.g., tropopause height), with increasing residuals in the tropical regions. Potential sources of temperature-related error in this region are errors in the temperature dependence of the $\mathrm{CO}_{2}$ half-widths and first-order line-coupling coefficients, as well as the lack of temperature dependence in the MT_CKD calculated $\mathrm{CO}_{2}$ continuum in this region. As the channels in the 755 to $770 \mathrm{~cm}^{-1}$ region are more sensitive to the lower troposphere, and the optical depths of $\mathrm{CO}_{2}$ and $\mathrm{H}_{2} \mathrm{O}$ are comparable in this region, it is possible that either 

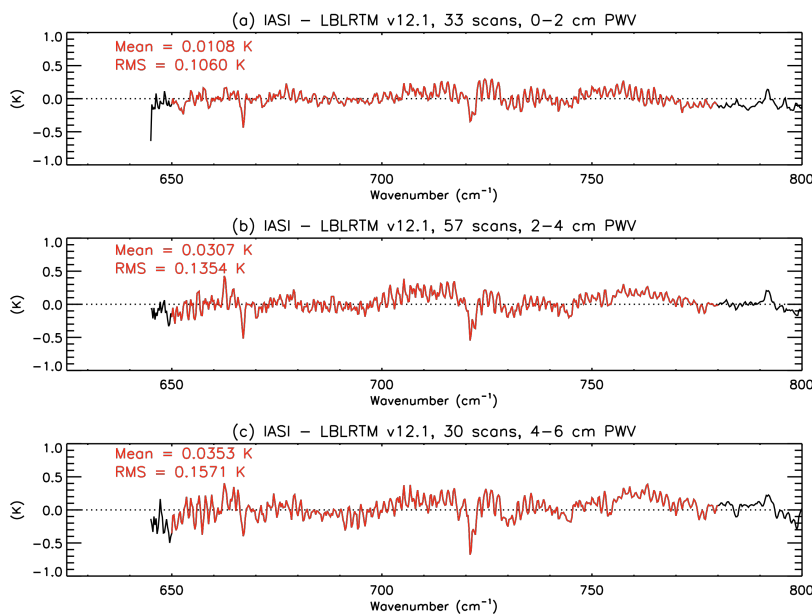

Fig. 5. Mean final (a posteriori) brightness temperature residuals in the $\mathrm{CO}_{2} v_{2}$ band using LBLRTM v12.1 as in Fig. 3b, but only for profiles with (a) 0 to $2 \mathrm{~cm}$, (b) 2 to $4 \mathrm{~cm}$, and (c) 4 to $6 \mathrm{~cm}$ of precipitable water vapor (PWV).

$\mathrm{CO}_{2}$ or $\mathrm{H}_{2} \mathrm{O}$ spectroscopic errors could be responsible for the residuals in this region.

The residuals in the $667 \mathrm{~cm}^{-1} \mathrm{Q}$-branch of $\mathrm{CO}_{2}$ are greatly improved from the study of Shephard et al. (2009), where the residuals between LBLRTM calculations and IASI measurements in this region were $\sim 1.7 \mathrm{~K}$. This is because, following the study of Masiello et al. (2011), we now include the $667 \mathrm{~cm}^{-1}$ Q-branch in our temperature retrievals and allow the temperature near the stratopause $(\sim 1 \mathrm{hPa})$ to adjust. Our mean radiance residual of $-4.2 \times 10^{-8} \mathrm{~W} \mathrm{~cm}^{-2} \mathrm{ster}^{-1} \mathrm{~cm}$ $(-0.45 \mathrm{~K}$ in brightness temperature) is very similar to the remaining residual shown in Fig. 12 of Masiello et al. (2009). This improvement in the residuals is consistent with the hypothesis of Shephard et al. (2009) that the residual they observed at the $667 \mathrm{~cm}^{-1}$ Q-branch was most likely due to errors in the temperature profile in the upper stratosphere and mesosphere. However, the remaining residual is still too large to be accounted for by randomly distributed instrument noise: for the 120 scans considered here, the error in the mean residual due to noise should be only $6.5 \times$ $10^{-9} \mathrm{~W} \mathrm{~cm}^{-2}$ ster $^{-1} \mathrm{~cm}(0.07 \mathrm{~K}$ in brightness temperature $)$. This suggests that there is still a systematic error in the spectroscopy in this region, possibly due to errors in the line parameters (e.g., line positions) or due to non-Voigt line shapes (e.g., speed dependence and/or Dicke narrowing). However, it is also possible that the remaining residuals are due to nonspectroscopic effects, such as poor vertical resolution of the stratopause in our temperature retrieval levels. Further work is necessary to decide between these two potential sources of error.

Figure 7a shows the difference between the a posteriori (after all retrieval steps on the main line, or left side, of Fig. 1) and a priori temperature profiles for LBLRTM v12.1. The
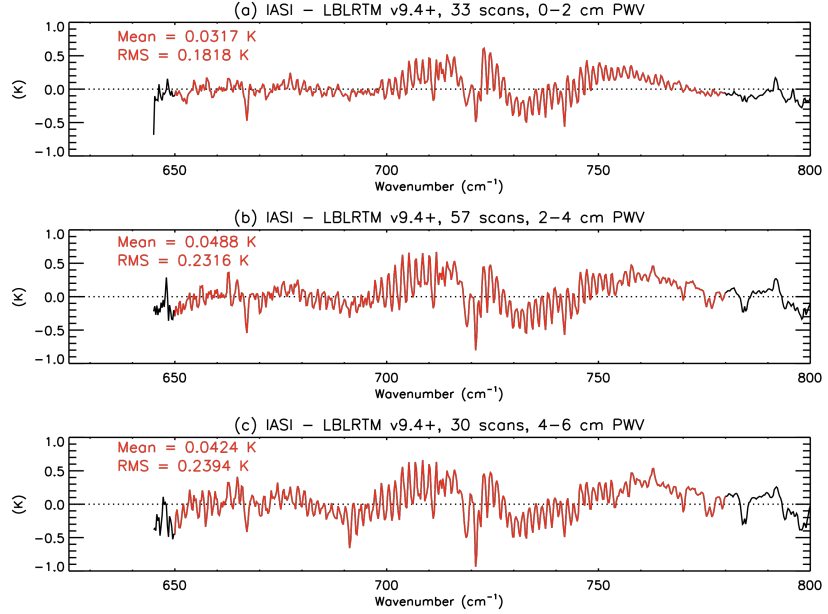

Fig. 6. Mean final (a posteriori) brightness temperature residuals in the $\mathrm{CO}_{2} v_{2}$ band using LBLRTM v9.4+ as in Fig. 3c, but only for profiles with (a) 0 to $2 \mathrm{~cm}$, (b) 2 to $4 \mathrm{~cm}$, and (c) 4 to $6 \mathrm{~cm}$ of precipitable water vapor (PWV).

thin red, green, and blue lines are the differences for the individual scans, with the color corresponding to a PWV of $0-2$, $2-4$, and $4-6 \mathrm{~cm}$, respectively. The thick black line shows the mean difference from the a priori over all 120 scans, with the black dashed lines showing the 25th and 75th percentiles. Figure $7 \mathrm{~b}$ shows the same comparison for LBLRTM v9.4+, while 7c shows the RMS differences between the a posteriori and a priori profiles for both v12.1 (black circles) and v9.4+ (red triangles). The RMS differences from the a priori temperature profiles are lower in v12.1 than in v9.4+ (with the slight exception of the $16.16 \mathrm{hPa}$ and $14.68 \mathrm{hPa}$ levels), as are the RMS differences of $T_{\text {sff }}(0.61 \mathrm{~K}$ in v12.1 versus $0.69 \mathrm{~K}$ in $\mathrm{v} 9.4+)$. The retrieved temperature profiles with the improved $\mathrm{CO}_{2}$ spectroscopy in LBLRTM v12.1 are thus more consistent with the forecast profiles, which draw on information from a wide range of in situ and remote sensing sources.

Figure 8 shows the differences between the temperature profiles retrieved using the updated $\mathrm{CO}_{2}$ spectroscopy in LBLRTM v12.1 versus those retrieved using LBLRTM v9.4+. (Note that in Fig. 8 and all similar plots in this paper, the error bars represent the variability, expressed as standard deviation, among the 120 cases analyzed, and do not represent the estimated error for a single retrieved profile.) Here both models used the $\nu_{2}$ band of $\mathrm{CO}_{2}$ to retrieve temperature. The differences between the two temperature profiles show an oscillatory structure versus altitude, consistent with the reduced oscillation in the residuals when LBLRTM v12.1 is used (see Fig. 3). Examination of the Jacobian from the temperature retrievals (not shown) suggests that the retrieved temperatures at altitudes below $500 \mathrm{hPa}$ are most sensitive to the P- and R-branches on the left and right of the $720 \mathrm{~cm}^{-1}$ Q-branch (approximately $700-718 \mathrm{~cm}^{-1}$ and $722-750 \mathrm{~cm}^{-1}$ ), while the retrieved temperatures at altitudes 

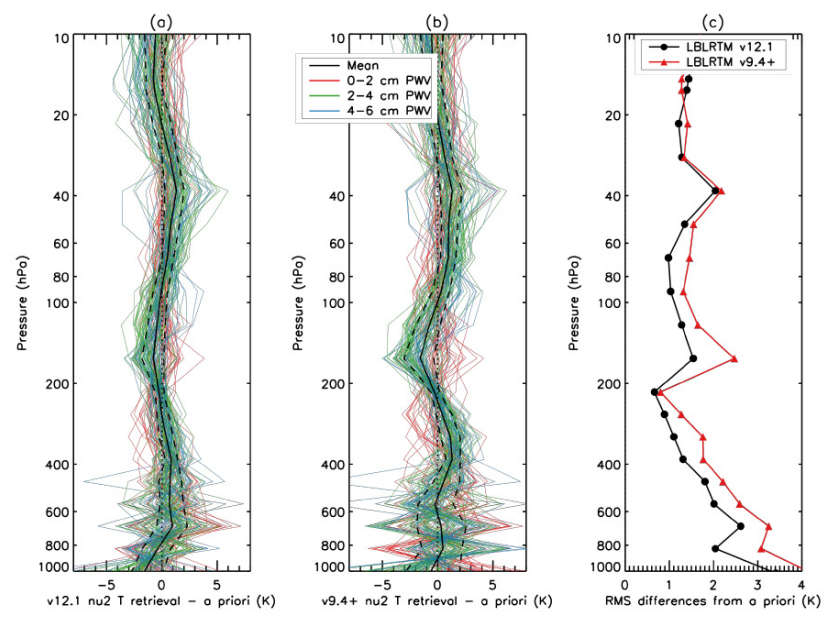

Fig. 7. (a) Differences between the final (a posteriori) temperature profile retrieved using LBLRTM v12.1 and the a priori temperature profiles. The thin red, green, and blue lines are the differences for the individual scans, and correspond to a PWV of 0-2, 2-4, and 4-6 cm, respectively. The thick black line shows the mean difference from the a priori over all 120 scans, with the black dashed lines showing the 25th and 75th percentiles. (b) As in (a), but for LBLRTM v9.4+. (c) RMS of the differences between the a posteriori and a priori temperature profiles for v12.1 (black circles) and $\mathrm{v} 9.4+$ (red triangles). The RMS difference of the surface (skin) temperature from the a priori is $0.61 \mathrm{~K}$ for $\mathrm{v} 12.1$ and $0.69 \mathrm{~K}$ for $\mathrm{v} 9.4+$.

above $500 \mathrm{hPa}$ are most sensitive to the spectroscopy of the $720 \mathrm{~cm}^{-1}$ Q-branch itself $\left(\sim 718-722 \mathrm{~cm}^{-1}\right)$. With the updated spectroscopy, the retrieved temperatures are on average $0.6 \pm 0.8 \mathrm{~K}$ higher at $562 \mathrm{hPa}$, consistent with the $\sim-0.5 \mathrm{~K}$ shift in the mean residuals in the wings surrounding the $720 \mathrm{~cm}^{-1}$ Q-branch as a result of the addition of P- and Rbranch line coupling to LBLRTM. The retrieved temperatures are on average $0.5 \pm 0.4 \mathrm{~K}$ lower in the upper troposphere near $300 \mathrm{hPa}, 0.8 \pm 0.7 \mathrm{~K}$ higher in the UTLS (upper troposphere-lower stratosphere) region between 100 and $200 \mathrm{hPa}, 0.4 \pm 0.4 \mathrm{~K}$ lower between 40 and $100 \mathrm{hPa}$, and $0.3 \pm 0.5 \mathrm{~K}$ lower between 10 and $30 \mathrm{hPa}$.

In our study, we assessed the consistency of the spectroscopy between the $\mathrm{CO}_{2} v_{2}$ and $v_{3}$ bands in two ways. First, we used the temperature profile retrieved using the $\mathrm{CO}_{2} v_{2}$ band to simulate the radiances in the $\nu_{3}$ band. (We discuss our second assessment method, comparing the temperature profiles retrieved using each band, further below.) Figure 9 shows the mean of the final and a priori residuals for both model versions in the $\mathrm{CO}_{2} \nu_{3}$ band for the 120 IASI spectra. The retrieval window for the $v_{3}$ atmospheric temperature retrieval is shown in green. These residuals are plotted in radiance units, as the low radiance values in this region (from the falloff of the Planck function) make a small change in radiance appear as a large change in brightness temperature. It is thus more constructive to view the residuals in this region in radiance units, but we note that the mean residuals

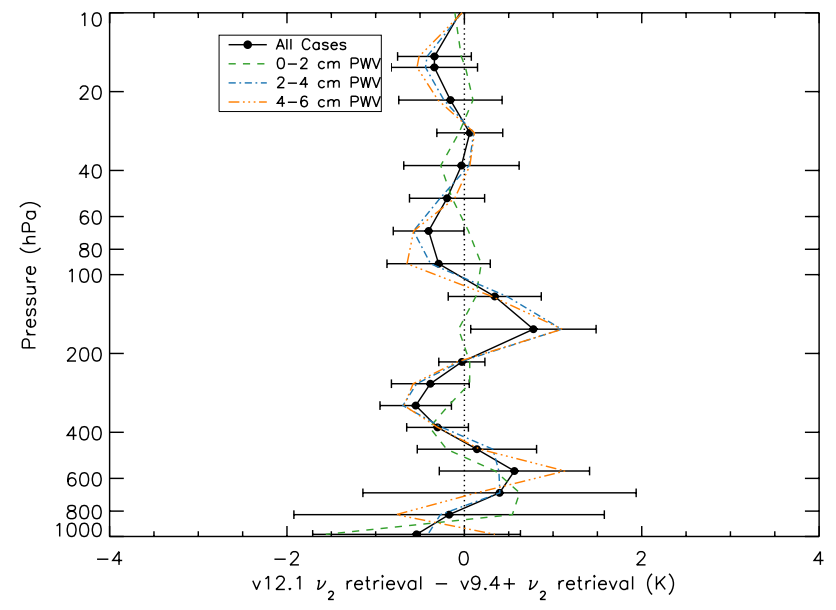

Fig. 8. Mean (solid line) and standard deviation (error bars) of the differences between the 120 temperature profiles retrieved with LBLRTM v12.1 and v9.4+. Dashed lines show the mean differences for the spectra with $0-2 \mathrm{~cm}$ (green), 2-4 cm (blue), and 4$6 \mathrm{~cm}$ (orange) PWV. Note that these temperature retrievals used the $\mathrm{CO}_{2} v_{2}$ band but not the $\mathrm{CO}_{2} v_{3}$ band.

throughout the IASI spectral range are presented in brightness temperature in Fig. 2.

Figure 9 shows that the spectroscopy in the $\mathrm{CO}_{2} v_{3}$ band has been greatly improved in LBLRTM v12.1, especially in the region past the band head $\left(2385-2500 \mathrm{~cm}^{-1}\right)$. However, a small systematic residual near the band head remains in LBLRTM v12.1. In addition, the large negative residuals between 2200 and $2270 \mathrm{~cm}^{-1}$ in both Fig. $9 \mathrm{~b}$ and c suggest that the optical depth in this region is still largely underestimated in LBLRTM v12.1. This is likely due to errors in the $\mathrm{N}_{2} \mathrm{O}, \mathrm{CO}_{2}$, and/or $\mathrm{H}_{2} \mathrm{O}$ spectroscopy in this spectral region, and we note that the updated $\mathrm{CO}_{2}, \mathrm{~N}_{2} \mathrm{O}$, and $\mathrm{H}_{2} \mathrm{O}$ spectroscopy in LBLRTM v12.1 has reduced the residuals in this region. There may also be a small contribution from errors in our $\mathrm{N}_{2} \mathrm{O}$ profiles. While our $\mathrm{N}_{2} \mathrm{O}$ profile should be fairly accurate in the troposphere (where $\mathrm{N}_{2} \mathrm{O}$ is a well-mixed gas), this spectral region is sensitive to $\mathrm{N}_{2} \mathrm{O}$ in the stratosphere, which can have a significant day-to-day variability (Randel et al., 1994). However, our calculations suggest that a $33 \%$ increase in our assumed stratospheric $\mathrm{N}_{2} \mathrm{O}$ would be required to remove a $-2 \times 10^{-9} \mathrm{~W} \mathrm{~cm}^{-2} \mathrm{ster}^{-1} \mathrm{~cm}(\sim 0.5 \mathrm{~K})$ residual in this region. While it is possible for midlatitude stratospheric $\mathrm{N}_{2} \mathrm{O}$ to vary by this amount, it is unlikely to have had a consistent bias of $33 \%$ across all 120 cases, and thus errors in the stratospheric $\mathrm{N}_{2} \mathrm{O}$ profile are unlikely to account for a large portion of the residuals seen in this region.

Figures 10 and 11 show the mean final (a posteriori) residuals in the $\mathrm{CO}_{2} v_{3}$ band for v12.1 and v9.4+, respectively, binned by PWV. The residuals in the $\mathrm{CO}_{2} \nu_{3}$ band in LBLRTM v12.1 have little dependence on water vapor, in contrast to the results for LBLRTM v9.4+, showing that the increase in the $\mathrm{H}_{2} \mathrm{O}$ self-continuum between 2385 and 


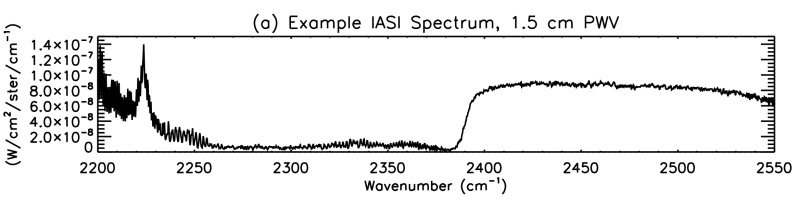

(b) IASI - LBLRTM v12.1, 120 scans
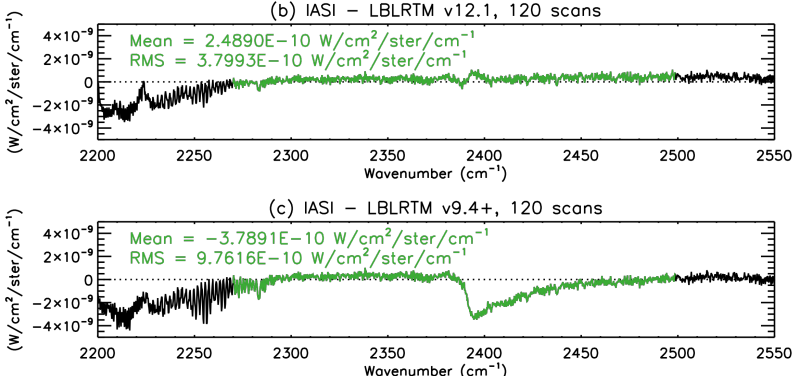

(d) IASI - LBLRTM v12.1 (a priori), 120 scans
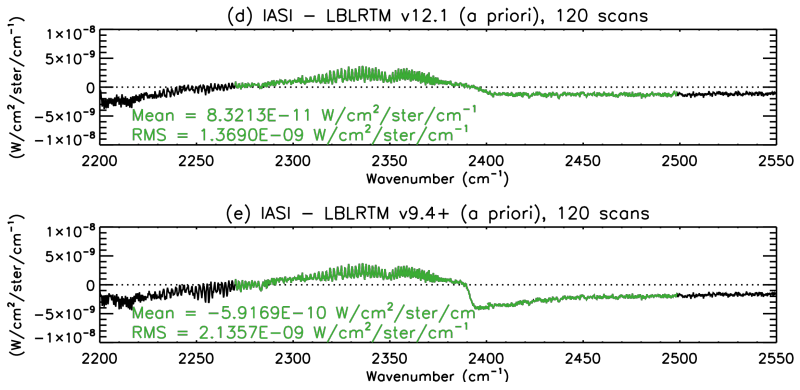

Fig. 9. (a) IASI-observed radiance spectrum in the $\nu_{3}$ band of $\mathrm{CO}_{2}$ for an example profile with $1.5 \mathrm{~cm}$ PWV. (b) Mean of the final (a posteriori) radiance residuals for 120 spectra using LBLRTM v12.1. (c) Mean of the final radiance residuals for 120 spectra using LBLRTM v9.4+. (d) Mean of the a priori radiance residuals for 120 spectra using LBLRTM v12.1. (e) Mean of the a priori radiance residuals for 120 spectra using LBLRTM v9.4+. The $\mathrm{CO}_{2} v_{3}$ band, which was not used in the temperature retrievals, is highlighted in green. Note that the RMS due to instrument noise alone in this band is $2.4 \times 10^{-10} \mathrm{~W} \mathrm{~cm}^{-2} \mathrm{ster}^{-1} \mathrm{~cm}$.

$2500 \mathrm{~cm}^{-1}$ in MT_CKD v2.5 reproduces well the observed absorption in this region (Mlawer et al., 2012). The selfcontinuum absorption in MT_CKD v2.5 in this spectral region is somewhat less than corresponding values determined in recent laboratory (Baranov et al., 2011; Ptashnik et al., 2011) and field studies (Strow et al., 2006). The results shown in Fig. 10c would permit a slight increase in the water vapor continuum optical depth past the $v_{3}$ band head, but this modification would negatively affect the residuals for cases with $2-4 \mathrm{~cm}$ of PWV (Fig. 10b). This also argues against increasing the $\mathrm{H}_{2} \mathrm{O}$ foreign continuum in this region, as suggested in the study of Ptashnik et al. (2012). Other recent work (e.g., Baranov et al., 2011, 2012) has suggested that the collision-induced $\mathrm{N}_{2}$ continuum in this region may be underestimated at high PWV, as collisions between $\mathrm{H}_{2} \mathrm{O}$ and $\mathrm{N}_{2}$ are more effective than collisions between $\mathrm{N}_{2}$ and air at inducing this absorption. We have not investigated the impact of this possible modification to the $\mathrm{N}_{2}$ continuum in
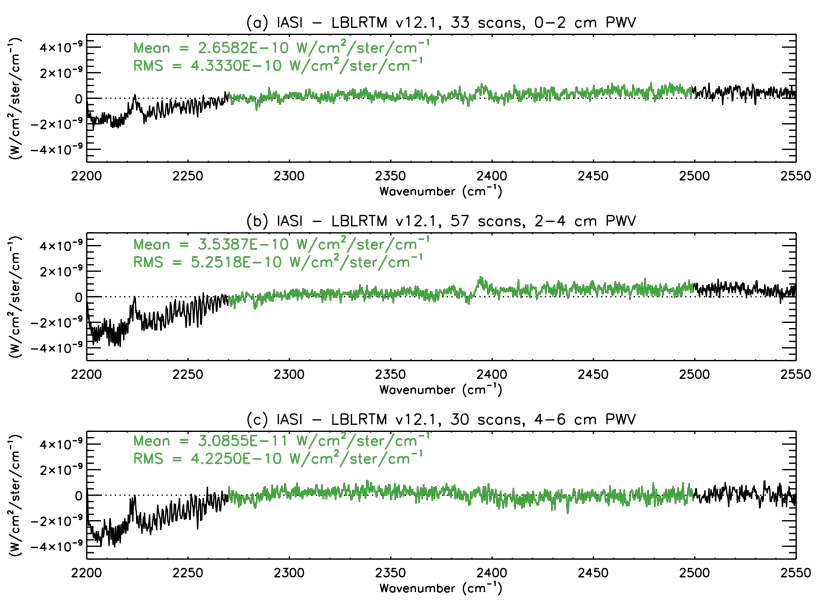

Fig. 10. Mean final (a posteriori) radiance residuals in the $\mathrm{CO}_{2} v_{3}$ band using LBLRTM v12.1 as in Fig. 7b, but only for profiles with (a) 0 to $2 \mathrm{~cm}$, (b) 2 to $4 \mathrm{~cm}$, and (c) 4 to $6 \mathrm{~cm}$ of precipitable water vapor.
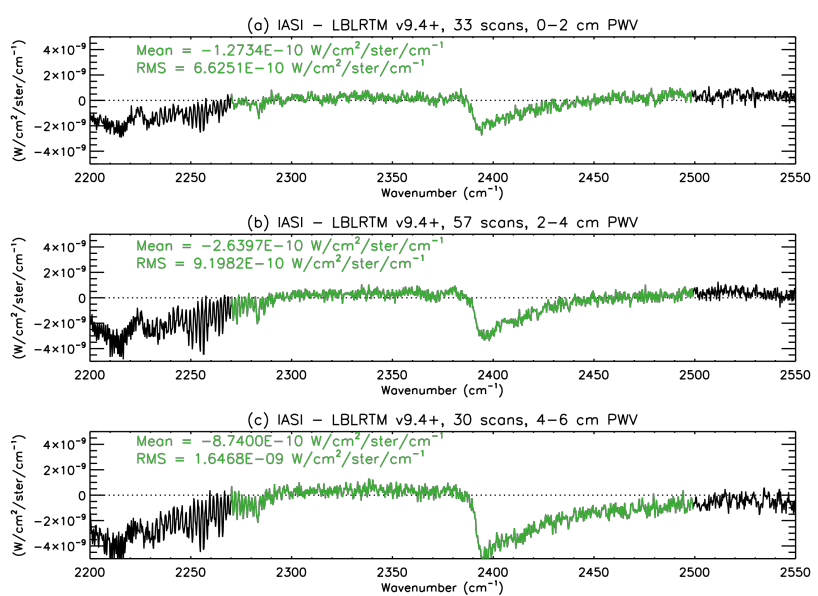

Fig. 11. Mean final (a posteriori) radiance residuals in the $\mathrm{CO}_{2} v_{3}$ band using LBLRTM v9.4+ as in Fig. 7c, but only for profiles with (a) 0 to $2 \mathrm{~cm}$, (b) 2 to $4 \mathrm{~cm}$, and (c) 4 to $6 \mathrm{~cm}$ of precipitable water vapor.

MT_CKD on the cases in the three PWV categories shown in Fig. 10.

The negative residuals between 2200 and $2270 \mathrm{~cm}^{-1}$, however, do appear to get more negative with increasing PWV. It is unlikely that this is due to issues with the MT_CKD water vapor continuum, as this explanation, when combined with our $\mathrm{CO}$ band results from Sect. 5.4 below, would require that the MT_CKD v2.5 $\mathrm{H}_{2} \mathrm{O}$ self-continuum be too low from 2200 to $2250 \mathrm{~cm}^{-1}$ but too high from 2050 to $2200 \mathrm{~cm}^{-1}$, which is unlikely. The standard deviation of the residuals about the mean is high in this region (generally of similar magnitude with the mean), and thus the apparent dependence of these residuals with PWV may not be statistically significant. 
A second test of the consistency of the spectroscopy in the $\mathrm{CO}_{2} v_{2}$ and $v_{3}$ bands is to evaluate the consistency of the atmospheric temperature profiles retrieved using each band. Generally, the $v_{3}$ retrievals have a lower number of degrees of freedom for signal (DOFS) than the $v_{2}$ retrievals (e.g., 7.1 vs. 10.3 for a moderate PWV IASI spectrum). Because of this, the retrievals should not be compared directly, as some of the differences between the retrievals will be due to the lower resolution of the $v_{3}$ retrievals. Instead, we smooth the $v_{2}$ retrievals by applying the averaging kernel and retrieved profile of the $v_{3}$ retrievals, following the procedure of Rodgers and Connor (2003). The smoothed $v_{2}$ temperature profile $\left(\hat{\boldsymbol{x}}_{v_{2}, \text { smooth }}\right)$ is calculated as

$\hat{\boldsymbol{x}}_{v_{2}, \text { smooth }}=\hat{\boldsymbol{x}}_{v_{3}}+\mathbf{A}_{v_{3}}\left(\hat{\boldsymbol{x}}_{v_{2}}-\hat{\boldsymbol{x}}_{v_{3}}\right)$,

where $\hat{\boldsymbol{x}}_{v_{2}}$ is the retrieved $\nu_{2}$ temperature profile, $\hat{\boldsymbol{x}}_{v_{3}}$ the retrieved $v_{3}$ temperature profile, and $\mathbf{A}_{v_{3}}$ the averaging kernel of the $v_{3}$ temperature retrieval. The differences between these smoothed $v_{2}$ temperature retrievals and the $v_{3}$ retrievals can thus illustrate inconsistencies in the modeling of these two spectral regions.

Figure $12 \mathrm{a}$ shows the mean and standard deviation of the differences between the $v_{3}$ and $v_{2}$ temperature retrievals before smoothing for both model versions, while Fig. 12b shows the same information after applying the smoothing as in Eq. (2). Figure 13 shows the smoothed differences binned by PWV. All of these plots show that the mean differences between the temperature profiles are substantially reduced in LBLRTM v12.1, especially in the stratosphere. In addition, the differences show less dependence on PWV in LBLRTM v12.1, again demonstrating the improved $\mathrm{CO}_{2}$ spectroscopy. However, significant differences $(-0.7 \pm 1.6 \mathrm{~K})$ still exist between the two retrieved temperature profiles in the middle troposphere. This appears to be caused by the fact that, in the $v_{3}$ temperature retrieval, the band head is the only region sensitive to middle tropospheric temperatures. Thus, this remaining discrepancy in middle tropospheric temperatures appears consistent with the small systematic residual feature near the band head seen in Fig. 9b.

\section{$5.2 \quad \mathrm{H}_{2} \mathrm{O} v_{2}$ band $\left(1350-2050 \mathrm{~cm}^{-1}\right)$}

Figure 14 shows the mean of the a posteriori brightness temperature residuals in the $\mathrm{H}_{2} \mathrm{O} v_{2}$ band for both LBLRTM v12.1 (Fig. 14b) and v9.4+ (Fig. 14c). The mean a priori residuals for each model are presented in Fig. 14d and e. The P-branch and R-branch $\mathrm{H}_{2} \mathrm{O}$ retrieval windows (1375.0-1560.0 $\mathrm{cm}^{-1}$ and $1640.0-2020.0 \mathrm{~cm}^{-1}$, respectively) are shown in red in these panels, which also show the mean and root mean square of the residuals in each window. The updated $\mathrm{H}_{2} \mathrm{O}$ spectroscopy in LBLRTM v12.1 substantially reduces the RMS of the final a posteriori residuals in the $\mathrm{H}_{2} \mathrm{O}$ P-branch (to $0.27 \mathrm{~K}$ from $0.34 \mathrm{~K}$ ) and R-branch (to $0.31 \mathrm{~K}$ from $0.34 \mathrm{~K}$ ). While the $\mathrm{R}$-branch improvement is more modest, the updated spectroscopy has reduced several
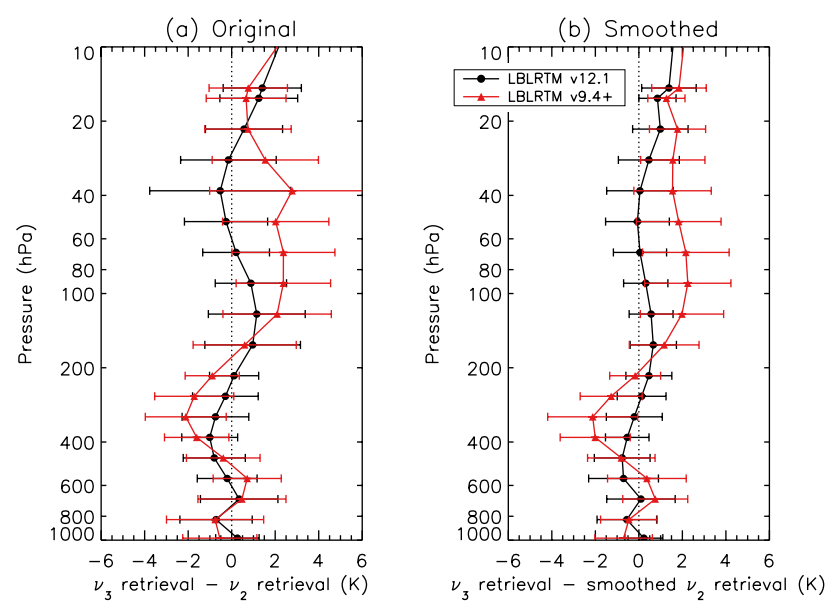

Fig. 12. Mean (solid line) and standard deviation (error bars) of the differences between the 120 temperature profiles retrieved with the $v_{3}$ band of $\mathrm{CO}_{2}$ and the profile retrieved with the $v_{2}$ retrieval. (a) The mean differences between the original profiles. (b) The mean differences between the profiles after the $v_{2}$ retrieval was smoothed using the averaging kernel of the $v_{3}$ retrieval, as described in the text.
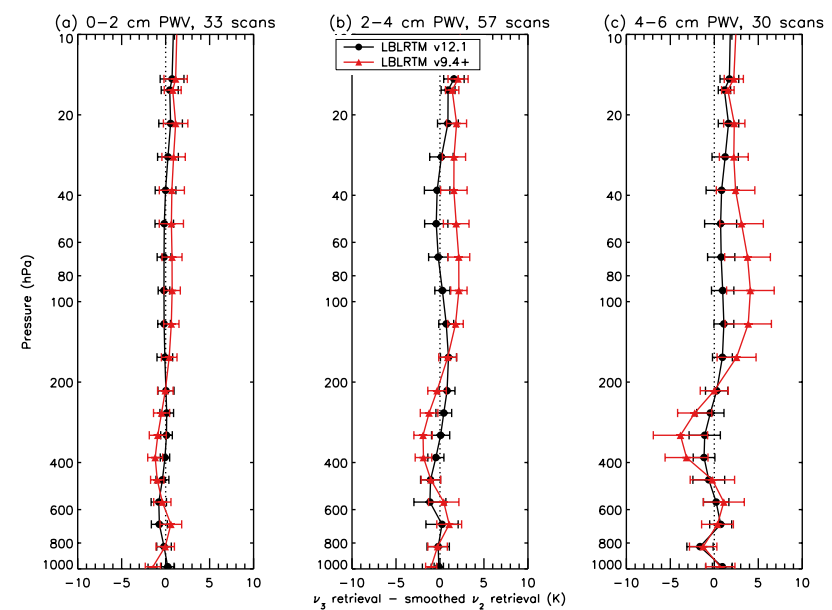

Fig. 13. As in Fig. 10b, but only for profiles with (a) 0 to $2 \mathrm{~cm}$, (b) 2 to $4 \mathrm{~cm}$, and (c) 4 to $6 \mathrm{~cm}$ of PWV.

features that were present in the LBLRTM v9.4+ R-branch residuals (e.g., the positive spikes near $1920 \mathrm{~cm}^{-1}$ ). Figures 15 and 16 show the mean final residuals in the $\mathrm{H}_{2} \mathrm{O} v_{2}$ band for v12.1 and v9.4+, respectively, binned by PWV. In both models, the P-branch RMS is largest for the cases with 2$4 \mathrm{~cm}$ PWV, while the R-branch residuals appear to increase steadily with PWV.

The RMS of the a priori residuals is larger in v12.1 than in v9.4+. However, in the P-branch the standard deviation about the mean for the a priori residuals is reduced from $0.349 \mathrm{~K}$ for $\mathrm{v} 9.4+$ to $0.326 \mathrm{~K}$ for $\mathrm{v} 12.1$. This suggests that the residuals within the P-branch are more consistent with 
(a) Example IASI Spectrum, $1.5 \mathrm{~cm}$ PWV

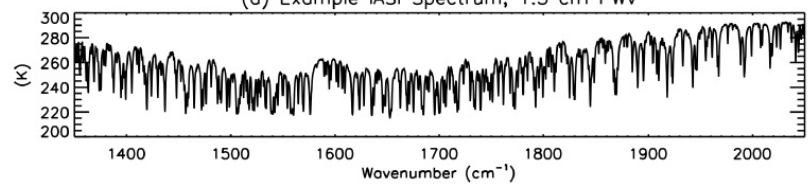

(b) IASI - LBLRTM v12.1, 120 scans

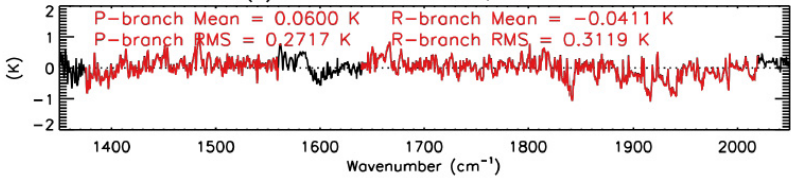

(c) IASI - LBLRTM v9.4+, 120 scans

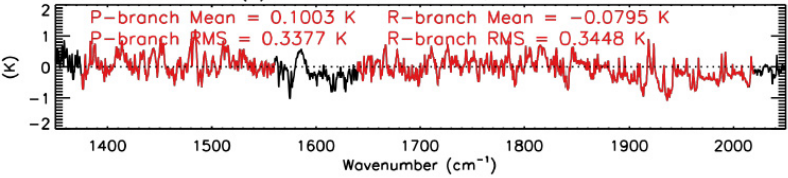

(d) IASI - LBLRTM v12.1 (a priori), 120 scans

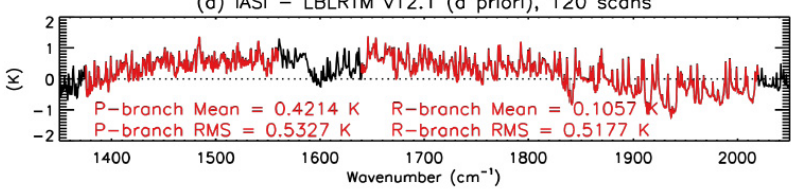

(e) IASI - LBLRTM v9.4+ (a priori), 120 scans

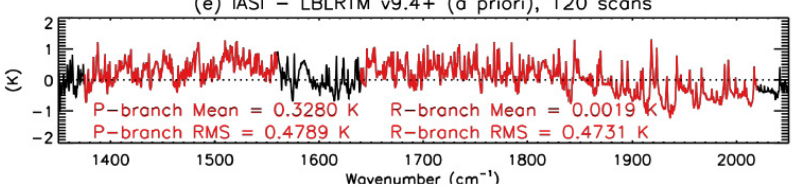

Fig. 14. (a) IASI-observed brightness temperature spectrum in the $v_{2}$ band of $\mathrm{H}_{2} \mathrm{O}$ for an example profile with $1.5 \mathrm{~cm}$ PWV. (b) Mean of the final (a posteriori) brightness temperature residuals for 120 spectra using LBLRTM v12.1. (c) Mean of the final brightness temperature residuals for 120 spectra using LBLRTM v9.4+. (d) Mean of the a priori brightness temperature residuals for 120 spectra using LBLRTM v12.1. (e) Mean of the a priori brightness temperature residuals for 120 spectra using LBLRTM v9.4+. The P- and $\mathrm{R}$-branch $\mathrm{H}_{2} \mathrm{O}$ retrieval windows are highlighted in red. Note that the RMS due to instrument noise alone in the P-branch is $0.041 \mathrm{~K}$ and in the R-branch is $0.088 \mathrm{~K}$.

each other in v12.1. In addition, Fig. 17 shows the residuals in the $\mathrm{H}_{2} \mathrm{O}$ band versus the measured brightness temperature for an example spectrum with $1.5 \mathrm{~cm}$ PWV, with the left column showing the a priori residuals and the right the a posteriori. Figure $17 \mathrm{a}$ and $\mathrm{b}$ show the results for the P-branch using v12.1, while Fig. 17c and d show the P-branch residuals using v9.4+. It is clear that there is a lot less spread in the P-branch channels with brightness temperatures less than $\sim 255 \mathrm{~K}$ (i.e., for the stronger $\mathrm{H}_{2} \mathrm{O}$ lines) in v12.1 than there was in $\mathrm{v} 9.4+$, whether you use the a priori or a posteriori results. This change is consistent with the work of Coudert et al. (2008), which generally increased the intensity of the strongest lines (in both the P- and R-branches) by 5-7\%. The changes in the R-branch (Fig. 17e-h) are less dramatic, and the standard deviation about the mean for the a priori residuals is increased in v12.1 relative to $\mathrm{v} 9.4+(0.507 \mathrm{~K}$ to $0.473 \mathrm{~K}$, respectively). However, the a posteriori residuals are (a) IASI - LBLRTM v12.1, 33 scans, 0-2 cm PW

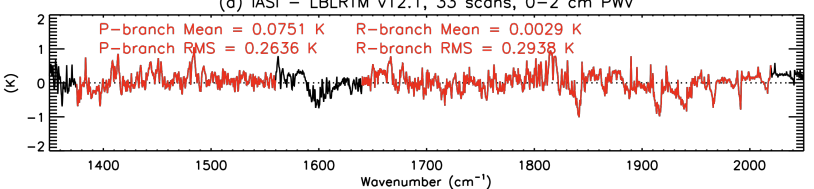

(b) IASI - LBLRTM V12.1, 57 scons, 2-4 cm PWV

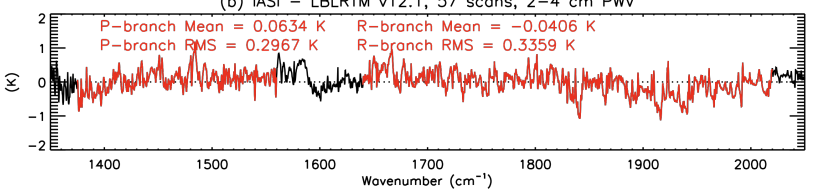

(c) IASI - LBLRTM v12.1, 30 scans, 4-6 cm PWV

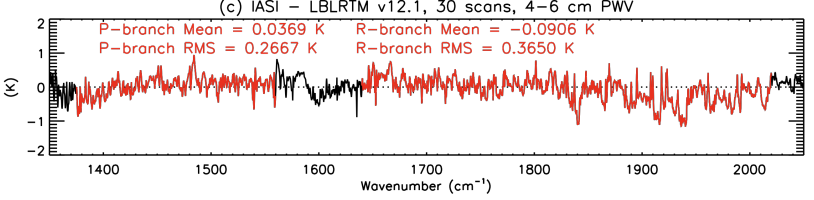

Fig. 15. Mean final (a posteriori) brightness temperature residuals in the $v_{2}$ band of $\mathrm{H}_{2} \mathrm{O}$ using LBLRTM v12.1 as in Fig. 12b, but only for profiles with (a) 0 to $2 \mathrm{~cm}$, (b) 2 to $4 \mathrm{~cm}$, and (c) 4 to $6 \mathrm{~cm}$ of precipitable water vapor.

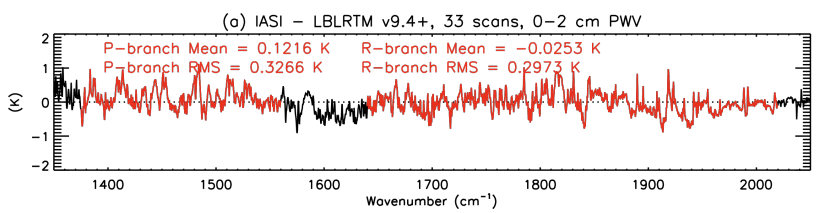

(b) IASI - LBLRTM v9.4+, 57 scans, $2-4 \mathrm{~cm}$ PWV

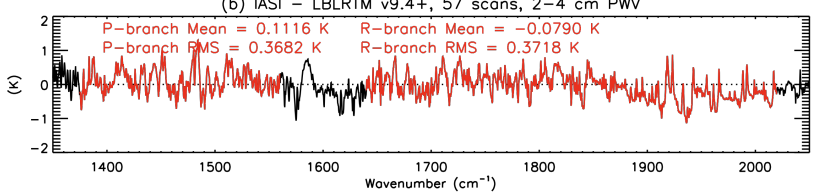

(c) IASI - LBLRTM v9.4+, 30 scans, $4-6 \mathrm{~cm}$ PWV

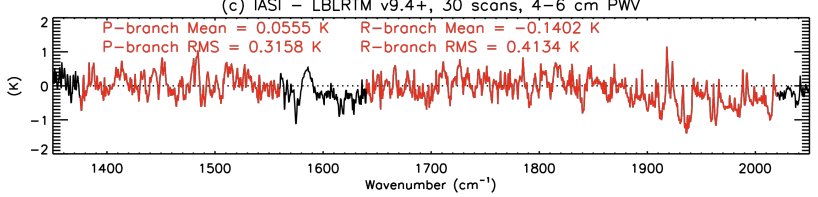

Fig. 16. Mean final (a posteriori) brightness temperature residuals in the $v_{2}$ band of $\mathrm{H}_{2} \mathrm{O}$ using LBLRTM v9.4+ as in Fig. 12c, but only for profiles with (a) 0 to $2 \mathrm{~cm}$, (b) 2 to $4 \mathrm{~cm}$, and (c) 4 to $6 \mathrm{~cm}$ of precipitable water vapor.

a little more "flat" (i.e., less correlated with brightness temperature and with a slope closer to 0 ) in v12.1 than in v9.4+, but not dramatically so.

The remaining residuals in the $\mathrm{H}_{2} \mathrm{O} \nu_{2}$ band could reflect errors in either the $\mathrm{H}_{2} \mathrm{O}$ line parameters or the $\mathrm{H}_{2} \mathrm{O}$ selfand foreign continua. In discussing the remaining residuals in the P-branch, one additional issue to consider is the error induced by mis-specification of the isotopic ratios. In both versions of LBLRTM shown here, the abundances of minor isotopologues of all molecules are set to fixed ratios relative to the major isotopologue for that molecule. These reference ratios are consistent with the reference ratios used 

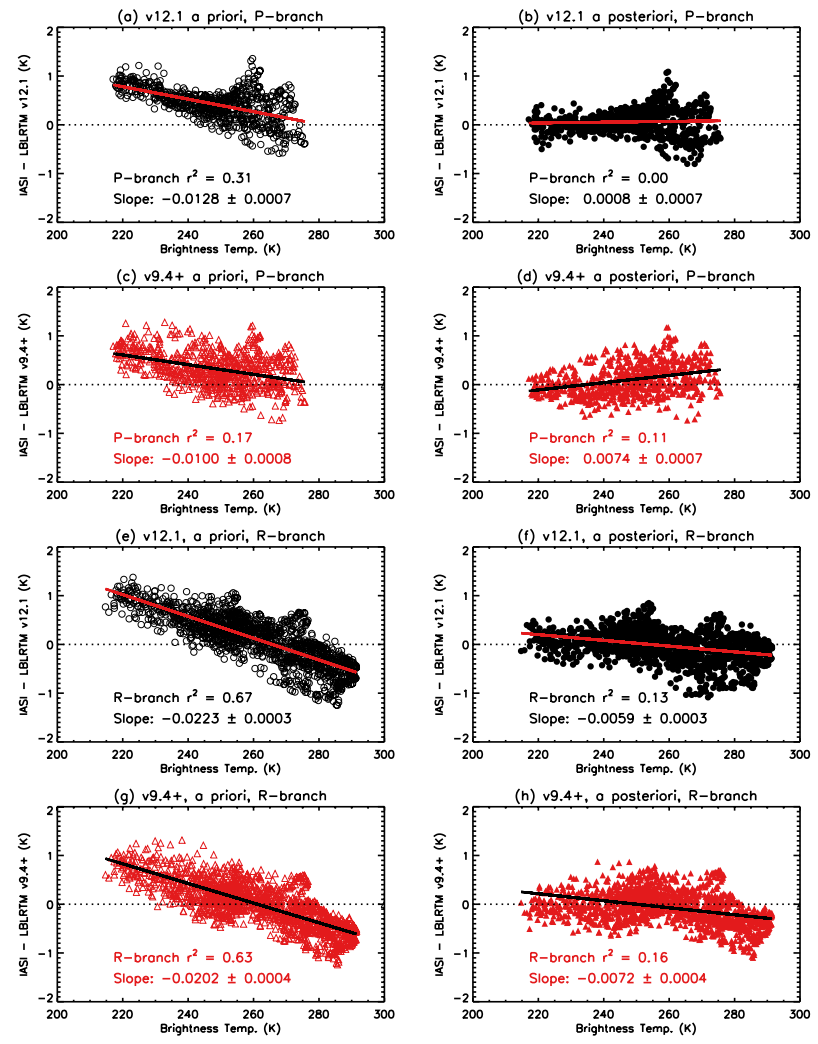

Fig. 17. A priori (left column, open symbols) and a posteriori (right column, closed symbols) mean residuals of 120 scans in the P- and R-branches of the $\mathrm{H}_{2} \mathrm{O} v_{2}$ band versus observed brightness temperature for an example spectrum with $1.5 \mathrm{~cm}$ PWV. Black circles are for residuals from v12.1, while red triangles are for residuals from v9.4+.

in the HITRAN database. However, atmospheric profiles of these ratios may vary substantially from these default reference values. In particular, atmospheric water vapor is always depleted in minor isotopologues relative to the reference standard, and the isotopic ratios show substantial variations in space (both vertically and horizontally) and time due to condensation/evaporation processes in the atmosphere (e.g., Worden et al., 2006, 2007, 2012; Nassar et al., 2007; Payne et al., 2007). This effect is most strongly pronounced for HDO. As HDO has substantial spectral features in the P-branch of the $\mathrm{H}_{2} \mathrm{O} \nu_{2}$ band, the fixed $\mathrm{HDO} / \mathrm{H}_{2} \mathrm{O}$ ratio in LBLRTM v12.1 could be responsible for some of the remaining residual features seen in Fig. 12b.

For example, Fig. 18 shows the P-branch residuals for a high water vapor spectrum $(5.4 \mathrm{~cm}$ PWV) immediately after the $\mathrm{P}$ - and R-branch retrieval of $\mathrm{H}_{2} \mathrm{O}$, plotted against the optical depth of HDO in each channel (calculated assuming the HITRAN reference ratio). The original LBLRTM v12.1 results are plotted as black circles. We can see that there is a clear upward trend in the residuals as HDO optical depth increases, suggesting that LBLRTM v12.1 is on aver-

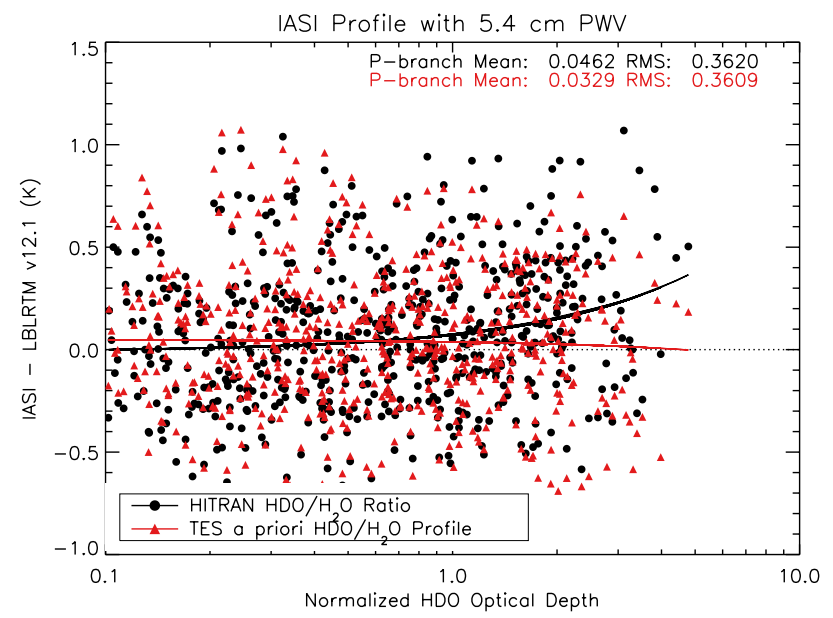

Fig. 18. LBLRTM v12.1 a posteriori (after $\mathrm{H}_{2} \mathrm{O}$ retrieval) brightness temperature residuals versus HDO optical depth for a profile with $5.4 \mathrm{~cm}$ PWV. The black circles show the results when the constant HITRAN $\mathrm{HDO} / \mathrm{H}_{2} \mathrm{O}$ ratio is used, while the red triangles show the results when the TES a priori profile of the $\mathrm{HDO} / \mathrm{H}_{2} \mathrm{O}$ ratio is used. The black and red lines are the corresponding leastsquares linear fits.

age overestimating the optical depth of HDO for this case. This is consistent with what we know about the real atmosphere, which is nearly always depleted in HDO relative to the HITRAN reference ratio. The red triangles show the same model results when the $\mathrm{HDO} / \mathrm{H}_{2} \mathrm{O}$ ratio is set to the uniform climatology used in the Aura TES retrievals and the $\mathrm{H}_{2} \mathrm{O}$ retrieval is repeated. In order to model this vertically varying $\mathrm{HDO} / \mathrm{H}_{2} \mathrm{O}$ ratio in LBLRTM, we temporarily added HDO as a separate molecule and removed the HDO lines from the $\mathrm{H}_{2} \mathrm{O}$ line parameters. This removed the bias between the channels sensitive to HDO (i.e., channels with HDO optical depths > 1.0) and the rest of the P-branch channels. This also very slightly reduces the RMS of the P-branch residuals from $0.362 \mathrm{~K}$ to $0.361 \mathrm{~K}$. (The small effect is expected as only a small number of P-branch channels are sensitive to HDO.) In addition, $29 \%$ of the remaining mean bias in the P-branch is removed by using the new HDO a priori, suggesting that errors in the HDO profile are responsible for a significant fraction of the remaining positive bias in the P-branch of the $\mathrm{H}_{2} \mathrm{O} v_{2}$ band relative to the R-branch (see Fig. 14). Note that the same exercise could be performed for $\mathrm{H}_{2}^{18} \mathrm{O}$ and $\mathrm{H}_{2}^{17} \mathrm{O}$. The deviation of isotopic ratios from the reference standard is $\sim 5$ times smaller for these isotopologues than for HDO, but their atmospheric abundances are considerably larger.

We also examined how the differences in $\mathrm{H}_{2} \mathrm{O}$ line parameters between HITRAN 2008 and the AER v3.1 parameters used in LBLRTM v12.1 impacted the spectral residuals that remain after the corresponding P- and R-branch $\mathrm{H}_{2} \mathrm{O}$ retrievals. As discussed in Sect. 2.2, HITRAN 2008 did not adopt the calculated line positions and intensities from 

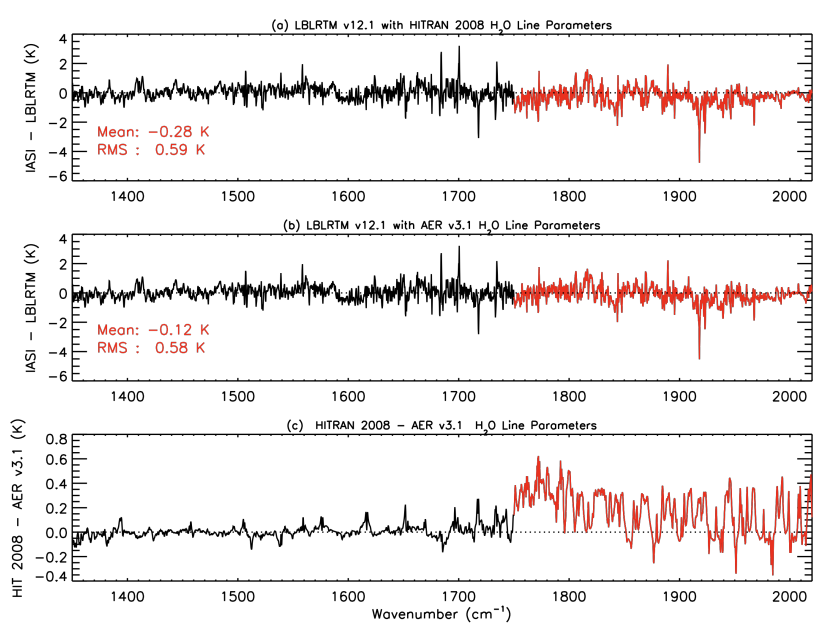

Fig. 19. (a) Brightness temperature residuals for an example profile with $1.5 \mathrm{~cm}$ PWV after the $\mathrm{H}_{2} \mathrm{O} \mathrm{P}$ - and R-branch retrieval when the HITRAN $2008 \mathrm{H}_{2} \mathrm{O}$ line parameters are used in LBLRTM v12.1. (b) Same as (a) but for the AER v3.1 line parameters used in LBLRTM v12.1 in the rest of this study. (c) Difference between (b) and (a), showing the discontinuity at wavenumbers greater than $\sim 1750 \mathrm{~cm}^{-1}$, where HITRAN 2008 does not use the Coudert et al. (2008) line positions and intensities included in AER v3.1.

Coudert et al. (2008), which are the primary source of these line parameters in AER v3.1 in the $1750-2500 \mathrm{~cm}^{-1}$ range. Figure 19a shows the residuals for a moderate PWV case after the $\mathrm{H}_{2} \mathrm{O}$ retrieval when the HITRAN $2008 \mathrm{H}_{2} \mathrm{O}$ line parameters are used in LBLRTM v12.1. Figure 19b shows the same for a standard run of LBLRTM v12.1 using the AER v3.1 $\mathrm{H}_{2} \mathrm{O}$ line parameters, and Fig. 19c shows the difference between the two model runs. The two sets of line parameters agree fairly well for wavenumbers below $1750 \mathrm{~cm}^{-1}$, but above this wavenumber the HITRAN 2008 parameters give generally larger brightness temperatures than AER v3.1. This region of substantial disagreement between HITRAN 2008 and AER v3.1 (1750-2020 $\left.\mathrm{cm}^{-1}\right)$ is highlighted in red in Fig. 19, and the mean and RMS of the residuals in this range are given as well. We can see in Fig. 19c that the HITRAN $2008 \mathrm{H}_{2} \mathrm{O}$ parameters appear to have a discontinuity between the parts of the $\mathrm{H}_{2} \mathrm{O} \nu_{2}$ band above and below $1750 \mathrm{~cm}^{-1}$ due to the exclusion of the calculated Coudert et al. (2008) parameters. We extended this analysis to two other example cases, corresponding to low $(0.3 \mathrm{~cm})$ and high $(5.4 \mathrm{~cm})$ values of PWV. Table 3 shows the mean and RMS of the residuals for these spectra using both HITRAN 2008 and AER v3.1 $\mathrm{H}_{2} \mathrm{O}$ line parameters. We examine three spectral ranges: the P-branch retrieval window $\left(1375-1560 \mathrm{~cm}^{-1}\right)$, the R-branch retrieval window $\left(1640-2020 \mathrm{~cm}^{-1}\right)$ and the "region of disagreement" in the R-branch $\left(1750-2020 \mathrm{~cm}^{-1}\right)$. We can then examine the differences in the mean bias between these subregions. For example, the difference in the mean bias between the P- and R-branches is higher in HITRAN 2008 than in AER v3.1, suggesting that the P- and R-branches are less consistent in HITRAN 2008 than in AER v3.1. Furthermore, when the mean bias in the R-branch as a whole is compared with the $1750-2020 \mathrm{~cm}^{-1}$ sub-region, it is clear that the $\mathrm{H}_{2} \mathrm{O}$ spectroscopy in AER v3.1 is more consistent across the Rbranch than HITRAN 2008. This suggests that the exclusion of the calculated Coudert et al. (2008) parameters in HITRAN 2008 leads to an unphysical discontinuity in the spectra near $1750 \mathrm{~cm}^{-1}$, with negative impacts on the spectral residuals in the R-branch of the $\mathrm{H}_{2} \mathrm{O} v_{2}$ band. (However, it should be noted that HITRAN 2008 is more self-consistent than AER v3.1 within the $1750-2020 \mathrm{~cm}^{-1}$ sub-region.) In contrast, using the full set of the Coudert et al. (2008) line positions and intensities between 10 and $2500 \mathrm{~cm}^{-1}$, as in LBLRTM v12.1 and AER v3.1, results in more consistent spectroscopy within the R-branch.

It is also possible that the improvement in the $\mathrm{H}_{2} \mathrm{O} v_{2}$ band residuals in LBLRTM v12.1 is not due to improved water vapor spectroscopy, but instead is due to the improvements in the $\mathrm{CO}_{2}$ spectroscopy, which then gives a better estimate of the temperature profile and thus results in better modeling of the $\mathrm{H}_{2} \mathrm{O} \nu_{2}$ band. To examine this possibility, we ran two additional $\mathrm{H}_{2} \mathrm{O}$ retrievals for our three representative cases: one that used the temperature profile retrieved by LBLRTM v9.4+ but used LBLRTM v12.1 (with its updated $\mathrm{H}_{2} \mathrm{O}$ spectroscopy) as the forward model, and another that used the temperature profile retrieved by LBLRTM v12.1 but used LBLRTM v9.4+ (with its older $\mathrm{H}_{2} \mathrm{O}$ spectroscopy) as the forward model. We performed these additional retrievals using both the $\mathrm{P}$ - and R-branches of the $\mathrm{H}_{2} \mathrm{O} \nu_{2}$ band. This gave us three cases with four different water vapor retrievals each, corresponding to the 4 possible combinations of retrieved temperature profile and $\mathrm{H}_{2} \mathrm{O}$ spectroscopy.

Table 4 shows the mean and RMS of the residuals in the $\mathrm{H}_{2} \mathrm{O} \mathrm{P}$ - and R-branch retrieval windows for the three cases and four combinations discussed above. Note that this comparison is looking at the residuals immediately after the $\mathrm{H}_{2} \mathrm{O}$ retrieval, rather than at the end of the entire retrieval procedure as in Figs. 14-16. This means that the results in Table 4 do not include the impact of the second constrained temperature retrieval that was performed after the $\mathrm{H}_{2} \mathrm{O}$ retrieval. Table 4 shows that both the improved temperature profiles and the updated $\mathrm{H}_{2} \mathrm{O}$ spectroscopy in LBLRTM v12.1 contribute to the improvements of the P-branch residuals for each case examined here. The results are more ambiguous in the R-branch. First, the R-branch RMS is the same or slightly higher for LBLRTM v12.1 than it was in LBLRTM v9.4+. This is consistent with the residuals averaged over all 120 scans immediately after the $\mathrm{H}_{2} \mathrm{O}$ retrieval (not shown), in which the mean R-branch RMS increases slightly from $0.28 \mathrm{~K}$ in $\mathrm{v} 9.4+$ to $0.29 \mathrm{~K}$ in $\mathrm{v} 12.1$. This suggests that the improvement in the RMS for the R-branch that we saw in Figs. 14-16 is mainly due to our second constrained temperature retrieval, rather than improvement in the $\mathrm{H}_{2} \mathrm{O}$ spectroscopy in this region. This is consistent with the results in 
Table 3. Water vapor retrieval brightness temperature residuals (mean and RMS in K, RMS in bold) for LBLRTM v12.1 when the $\mathrm{H}_{2} \mathrm{O}$ line parameters from HITRAN 2008 and those from AER v3.1 are used.

\begin{tabular}{|c|c|c|c|c|c|c|}
\hline & \multicolumn{2}{|c|}{$0.3 \mathrm{~cm}$ PWV } & \multicolumn{2}{|c|}{$1.5 \mathrm{~cm} \mathrm{PWV}$} & \multicolumn{2}{|c|}{$5.4 \mathrm{~cm} \mathrm{PWV}$} \\
\hline & AER v3.1 & HITRAN 2008 & AER v3.1 & HITRAN 2008 & AER v3.1 & HITRAN 2008 \\
\hline P-branch $\left(1375-1560 \mathrm{~cm}^{-1}\right)$ & $0.11(\mathbf{0 . 3 5})$ & $0.13(\mathbf{0 . 3 6})$ & $0.06(\mathbf{0 . 3 9})$ & $0.07(\mathbf{0 . 4 0})$ & $0.05(\mathbf{0 . 3 6})$ & $0.05(\mathbf{0 . 3 7})$ \\
\hline R-branch $\left(1640-2020 \mathrm{~cm}^{-1}\right)$ & $0.09(\mathbf{0 . 6 4 )}$ & $-0.02(\mathbf{0 . 6 6})$ & $-0.06(\mathbf{0 . 6 1})$ & $-0.18(\mathbf{0 . 6 6 )}$ & $-0.05(\mathbf{0 . 7 5})$ & $-0.19(\mathbf{0 . 7 9 )}$ \\
\hline R-branch $\left(1750-2020 \mathrm{~cm}^{-1}\right)$ & $0.12(\mathbf{0 . 6 3 )}$ & $-0.03(\mathbf{0 . 6 5})$ & $-0.12(\mathbf{0 . 5 8})$ & $-0.28(\mathbf{0 . 5 9})$ & $-0.13(\mathbf{0 . 7 5 )}$ & $-0.31(\mathbf{0 . 8 0})$ \\
\hline
\end{tabular}

Table 4. Water vapor retrieval brightness temperature residuals (mean and RMS in K, RMS in bold) for different combinations of retrieved temperature profiles and $\mathrm{H}_{2} \mathrm{O}$ spectroscopy.

\begin{tabular}{|c|c|c|c|c|c|c|}
\hline & \multicolumn{2}{|c|}{$0.3 \mathrm{~cm}$ PWV } & \multicolumn{2}{|c|}{$1.5 \mathrm{~cm}$ PWV } & \multicolumn{2}{|c|}{$5.4 \mathrm{~cm} \mathrm{PWV}$} \\
\hline & P-branch & R-branch & P-branch & R-branch & P-branch & R-branch \\
\hline New T, New $\mathrm{H}_{2} \mathrm{O}$ & $0.11(\mathbf{0 . 3 5})$ & $0.09(\mathbf{0 . 6 4 )}$ & $0.06(\mathbf{0 . 3 9})$ & $-0.06(\mathbf{0 . 6 1})$ & $0.05(\mathbf{0 . 3 6})$ & $-0.05(\mathbf{0 . 7 5})$ \\
\hline Old T, New $\mathrm{H}_{2} \mathrm{O}$ & $0.16(\mathbf{0 . 3 7})$ & $0.11(\mathbf{0 . 6 4 )}$ & $0.07(\mathbf{0 . 3 9})$ & $-0.06(\mathbf{0 . 5 9})$ & $0.05(\mathbf{0 . 3 7})$ & $-0.03(\mathbf{0 . 7 6})$ \\
\hline New T, Old $\mathrm{H}_{2} \mathrm{O}$ & $0.09(\mathbf{0 . 3 7})$ & $0.04(\mathbf{0 . 6 4 )}$ & $0.06(\mathbf{0 . 4 2})$ & $-0.08(\mathbf{0 . 5 8})$ & $0.04(\mathbf{0 . 3 8})$ & $-0.05(\mathbf{0 . 7 2})$ \\
\hline Old T, Old $\mathrm{H}_{2} \mathrm{O}$ & $0.13(\mathbf{0 . 3 9})$ & $0.05(\mathbf{0 . 6 4 )}$ & $0.07(\mathbf{0 . 4 1})$ & $-0.08(\mathbf{0 . 5 7})$ & $0.04(\mathbf{0 . 3 8})$ & $-0.05(\mathbf{0 . 7 3})$ \\
\hline
\end{tabular}
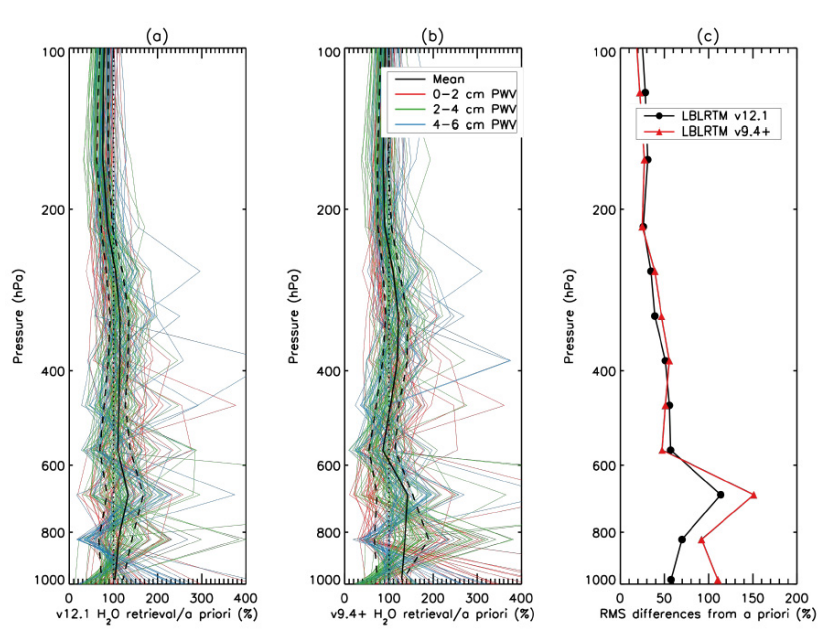

Fig. 20. (a) Ratio of the final a posteriori (retrieved) $\mathrm{H}_{2} \mathrm{O}$ profile using LBLRTM v12.1 to the a priori temperature profiles, as a percent. The thin red, green, and blue lines are the differences for the individual scans, and correspond to a PWV of $0-2,2-4$, and $4-6 \mathrm{~cm}$, respectively. The thick black line shows the mean ratio to the a priori over all 120 scans, with the black dashed lines showing the 25 th and 75th percentiles. (b) As in (a), but for LBLRTM v9.4+. (c) RMS of the percentage differences between the a posteriori and a priori $\mathrm{H}_{2} \mathrm{O}$ profiles for v12.1 (black circles) and v9.4+ (red triangles).

Table 4, where the RMS in the R-branch is higher when the new $\mathrm{H}_{2} \mathrm{O}$ spectroscopy is used, regardless of which temperature profile is used. Thus in the P-branch of the $\mathrm{H}_{2} \mathrm{O} v_{2}$ band, the decrease in the RMS of the mean residuals is likely due to a combination of the improvements in $\mathrm{H}_{2} \mathrm{O}$ spectroscopy and the improvements in the $\mathrm{CO}_{2}$ spectroscopy, while in the R-branch the improvements are mainly due to improvements in the $\mathrm{CO}_{2}$ spectroscopy and our second constrained temperature retrieval.

Both the $\mathrm{CO}_{2}$ and the $\mathrm{H}_{2} \mathrm{O}$ spectroscopic updates in LBLRTM v12.1 can also have a large impact on the retrieved profiles of $\mathrm{H}_{2} \mathrm{O}$. The $\mathrm{H}_{2} \mathrm{O}$ mixing ratios retrieved by LBLRTM v12.1 and LBLRTM v9.4+ can differ by a factor of 2 or more. Figure 20a shows the ratio (as a percent) of the a posteriori (after all retrieval steps) and a priori $\mathrm{H}_{2} \mathrm{O}$ profiles for LBLRTM v12.1. Figure 20b shows the same results for v9.4+, and Fig. 20c shows the RMS differences between the retrieved and a priori $\mathrm{H}_{2} \mathrm{O}$ profiles for both models. At altitudes below the $600 \mathrm{hPa}$ surface, LBLRTM v12.1 has a much smaller RMS difference from the a priori than v9.4+, while the two models have similar RMS values at higher altitudes. This shows that the updated $\mathrm{CO}_{2}$ and $\mathrm{H}_{2} \mathrm{O}$ spectroscopy in LBLRTM v12.1 gives $\mathrm{H}_{2} \mathrm{O}$ retrievals that are more consistent with the forecast relative to LBLRTM v9.4+.

Figure 21 shows the mean and standard deviation of the ratio of the LBLRTM v12.1 retrieved $\mathrm{H}_{2} \mathrm{O}$ profiles ( $\mathrm{P}$ - and $\mathrm{R}$ branch) to the v9.4+ retrieved profiles for the 120 IASI spectra. We can see that the new spectroscopy generally reduces the retrieved $\mathrm{H}_{2} \mathrm{O}$ mixing ratio between 100 and $200 \mathrm{hPa}$ by $14 \%$, with a variability (expressed as a standard deviation) among the cases of $\pm 8 \%$. This is consistent with the results of Shephard et al. (2009), who first showed that the addition of the Coudert et al. (2008) line positions and intensities to HITRAN 2004 resulted in a $10 \%$ reduction in the upper tropospheric $\mathrm{H}_{2} \mathrm{O}$ mixing ratio. At $562 \mathrm{hPa}$ the new spectroscopy increases the retrieved $\mathrm{H}_{2} \mathrm{O}$ mixing ratio by $42 \%$ on average, but the variability is very large $( \pm 58 \%)$. Near the surface, this variability is quite large (over a factor of 2), so even though the mean difference is $31 \%$ there can be dramatic differences for any given case. 


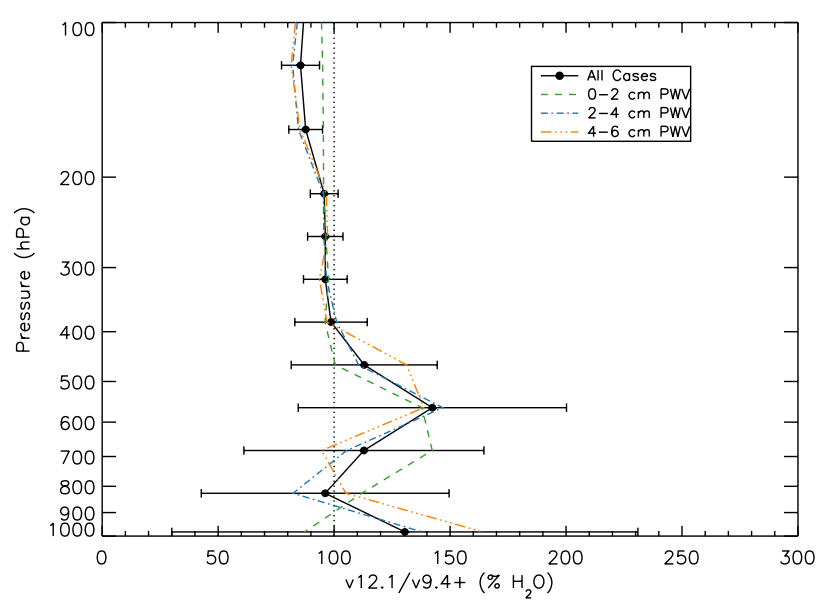

Fig. 21. Mean (black circles) and standard deviation (error bars) of the ratio of the 120 LBLRTM v12.1 retrieved $\mathrm{H}_{2} \mathrm{O}$ profiles to the v9.4+ retrieved profiles, expressed as a percent. Dashed lines show the mean differences for the spectra with $0-2 \mathrm{~cm}$ (green), $2-4 \mathrm{~cm}$ (blue), and 4-6 cm (orange) PWV. Both models used the P- and Rbranches in the retrievals.
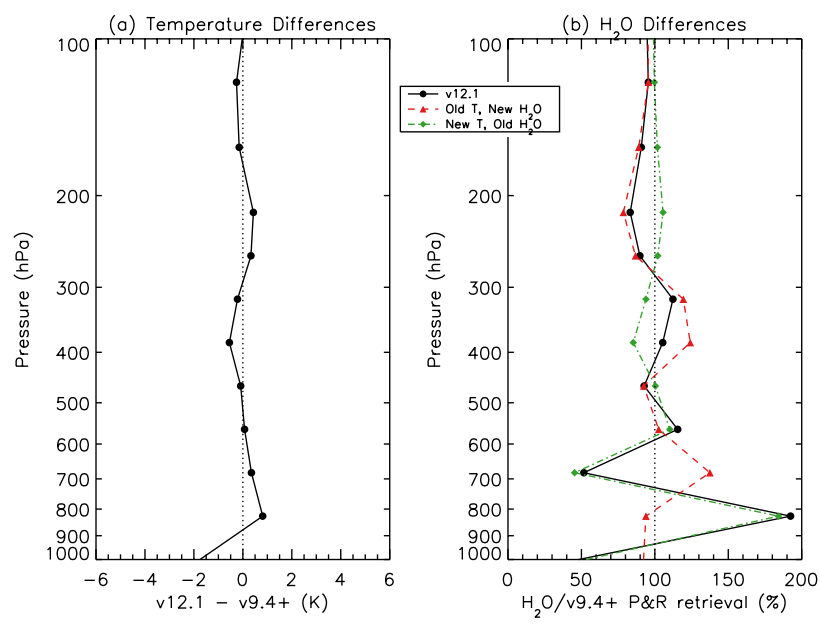

Fig. 22. (a) Difference of the retrieved temperature profiles between LBLRTM v12.1 and v9.4+ for an example spectrum with $1.5 \mathrm{~cm}$ PWV. The profiles were retrieved using the $\mathrm{CO}_{2} v_{2}$ band. (b) The $\mathrm{H}_{2} \mathrm{O}$ profile retrieved using (i) LBLRTM v12.1 to retrieve both temperature and $\mathrm{H}_{2} \mathrm{O}$ (black circles), (ii) LBLRTM v9.4+ to retrieve temperature and LBLRTM v12.1 to retrieve $\mathrm{H}_{2} \mathrm{O}$ (red triangles), and (iii) LBLRTM v12.1 to retrieve temperature and LBLRTM v9.4+ to retrieve $\mathrm{H}_{2} \mathrm{O}$ (green diamonds), all normalized by the profile retrieved using LBLRTM v9.4+ to retrieve both temperature and $\mathrm{H}_{2} \mathrm{O}$.

In order to examine whether $\mathrm{CO}_{2}$ or $\mathrm{H}_{2} \mathrm{O}$ spectroscopic changes between LBLRTM v12.1 and v9.4+ are primarily responsible for the changes in the retrieved $\mathrm{H}_{2} \mathrm{O}$ seen in Fig. 21, we analyzed the retrieved $\mathrm{H}_{2} \mathrm{O}$ profiles for our three representative cases and the 4 possible combinations of retrieved temperature profile and $\mathrm{H}_{2} \mathrm{O}$ spectroscopy (see
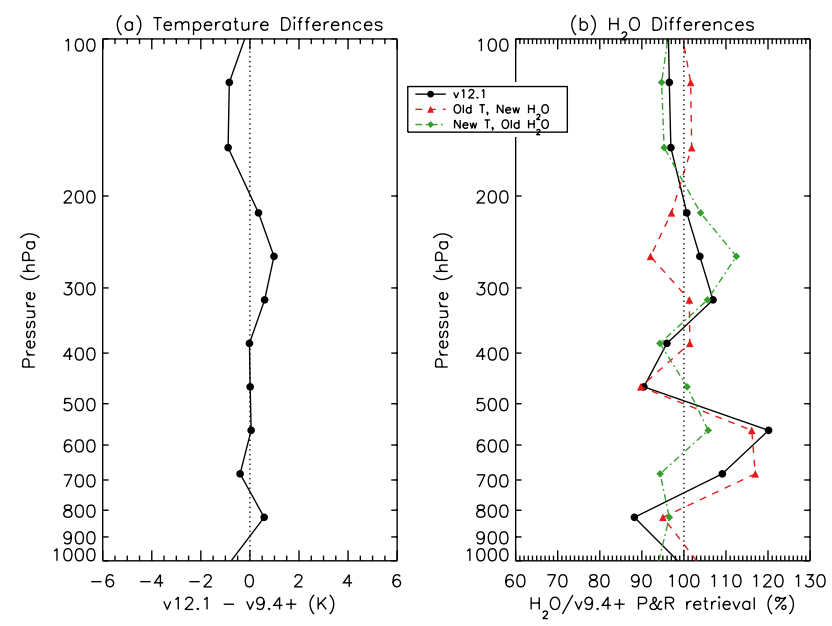

Fig. 23. Same as Fig. 18 but for an example spectrum with $0.3 \mathrm{~cm}$ PWV.

Table 4 and the discussion above). Figure 22 shows the (a) temperature differences and (b) retrieved $\mathrm{H}_{2} \mathrm{O}$ differences for our example case with 1.5 PWV. We plot three $\mathrm{H}_{2} \mathrm{O}$ profiles, which are the profiles retrieved using (i) LBLRTM v12.1 to retrieve both temperature and $\mathrm{H}_{2} \mathrm{O}$ (black circles), (ii) LBLRTM v9.4+ to retrieve temperature and LBLRTM v12.1 to retrieve $\mathrm{H}_{2} \mathrm{O}$ (red triangles), and (iii) LBLRTM v12.1 to retrieve temperature and LBLRTM v9.4+ to retrieve $\mathrm{H}_{2} \mathrm{O}$ (green diamonds). All three profiles are normalized by the $\mathrm{H}_{2} \mathrm{O}$ profile retrieved when LBLRTM v9.4+ is used to retrieve both temperature and $\mathrm{H}_{2} \mathrm{O}$.

For the moderate water vapor case (Fig. 22), the temperature change is relatively large $(>1.5 \mathrm{~K})$ near the surface, and this temperature change seems to be responsible for most of the lower troposphere water vapor changes. However, the reduction in $\mathrm{H}_{2} \mathrm{O}$ between $100 \mathrm{hPa}$ and $300 \mathrm{hPa}$ is primarily caused by the new $\mathrm{H}_{2} \mathrm{O}$ spectroscopy. Based on Shephard et al. (2009), this upper atmospheric change is more likely due to the inclusion of the Coudert et al. (2008) positions and intensities in AER v3.1, rather than the $\mathrm{H}_{2} \mathrm{O}$ width updates that were included in HITRAN 2008. In the low water vapor case (Fig. 23), the temperature differences are low, so the changes to $\mathrm{H}_{2} \mathrm{O}$ spectroscopy are primarily responsible for the changes in the retrieved $\mathrm{H}_{2} \mathrm{O}$ profile in this case, with the width changes likely more important in the lower troposphere. However, the high water vapor case (not shown) shows similar results to the moderate case, where temperature changes dominate in the lower troposphere. Thus, the observed mean changes in the retrieved $\mathrm{H}_{2} \mathrm{O}$ profile in Fig. 21 are likely due to a combination of the $\mathrm{H}_{2} \mathrm{O}$ spectroscopy changes and the temperature profile changes (themselves caused by $\mathrm{CO}_{2}$ spectroscopy changes), with the relative importance of each depending on the size of the temperature profile changes. 


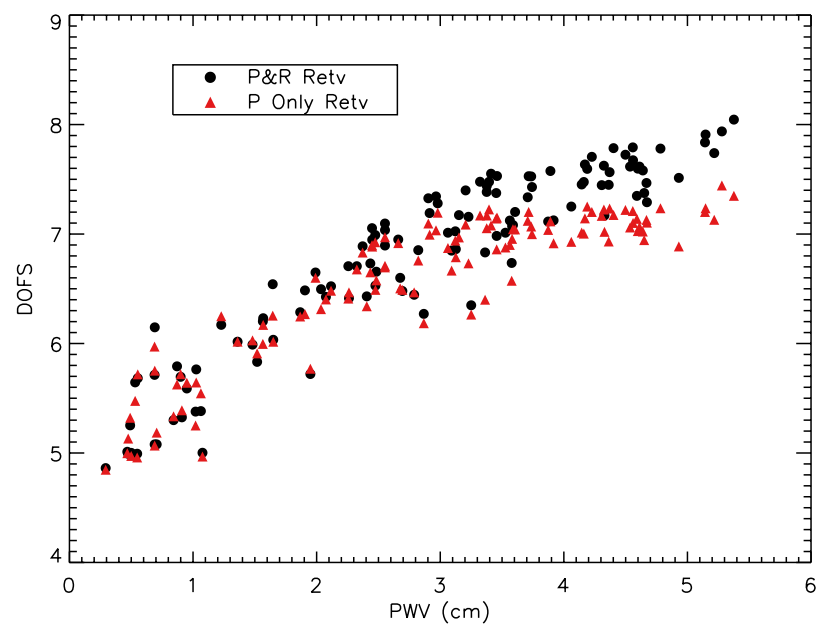

Fig. 24. Degrees of freedom for signal (DOFS) versus PWV for the P- and R-branch retrieval (black circles) and the P-branch-only retrieval (red triangles) of $\mathrm{H}_{2} \mathrm{O}$ using LBLRTM v12.1.

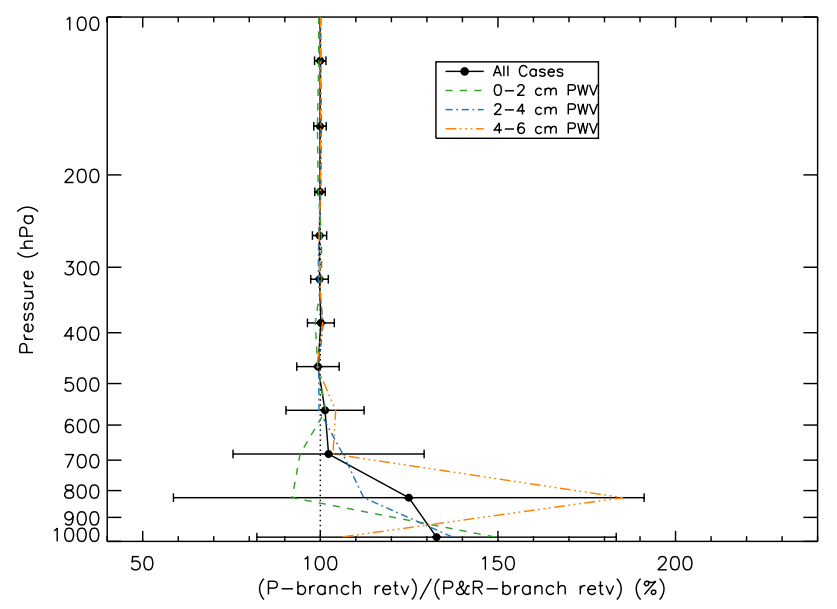

Fig. 25. Mean (black circles) and standard deviation (error bars) of the ratio of the $120 \mathrm{H}_{2} \mathrm{O}$ profiles retrieved with LBLRTM v12.1 using the $\mathrm{P}$ branch of the $v_{2}$ band of $\mathrm{H}_{2} \mathrm{O}$ to the profiles retrieved using both the P- and R-branches. Dashed lines show the mean differences for the spectra with 0-2 cm (green), 2-4 cm (blue), and 4-6 cm (orange) PWV.

Finally, we find that the R-branch can provide additional information on near-surface $\mathrm{H}_{2} \mathrm{O}$ that is not available from the P-branch due to the interference of $\mathrm{CH}_{4}$ and $\mathrm{N}_{2} \mathrm{O}$. This is shown in Fig. 24, which shows the DOFS versus PWV for the P- and R-branch retrieval (black circles) and the Pbranch-only retrieval (red triangles) of $\mathrm{H}_{2} \mathrm{O}$ using LBLRTM v12.1. We can see that the P- and R-branch retrieval generally has higher values for DOFS, and that the difference is largest for the moist cases. Examination of the averaging kernels for these moist cases (not shown) demonstrates that the additional information is primarily in the near-surface layers. This suggests that an instrument that uses both the P-

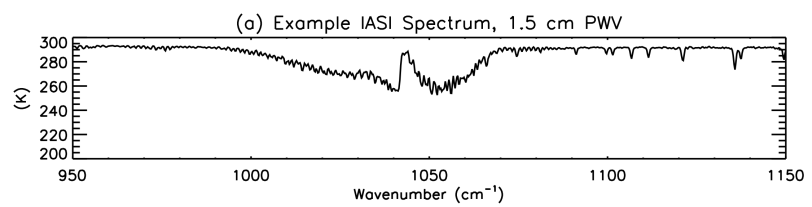

(b) IASI - LBLRTM v12.1, 120 scans

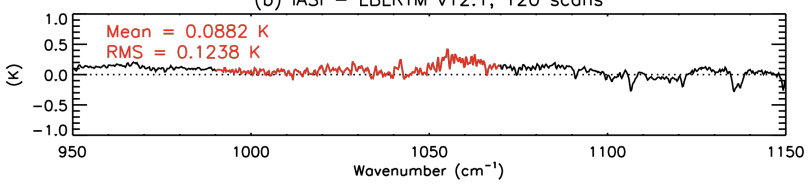

(c) IASI - LBLRTM v9.4+, 120 scans

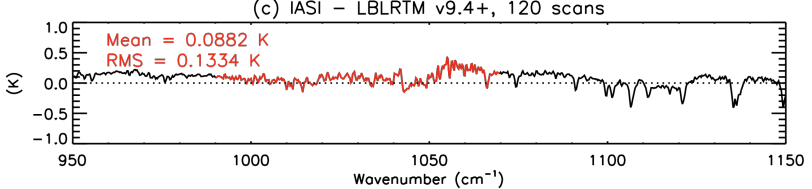

(d) IASI - LBLRTM v12.1 (a priori), 120 scans

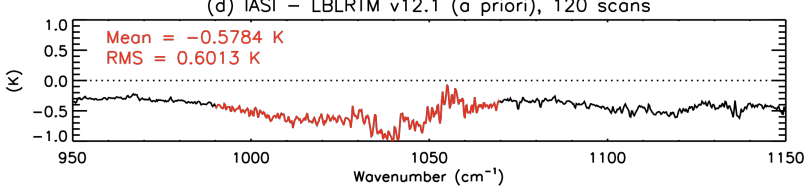

(e) IASI - LBLRTM v9.4+ (a priori), 120 scans

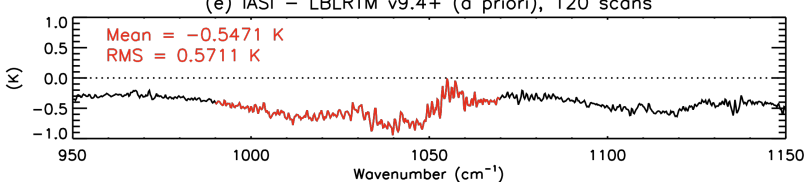

Fig. 26. (a) IASI-observed brightness temperature spectrum in the $v_{3}$ band of $\mathrm{O}_{3}$ for an example profile with $1.5 \mathrm{~cm}$ PWV. (b) Mean of the final (a posteriori) brightness temperature residuals for 120 spectra using LBLRTM v12.1. (c) Mean of the final brightness temperature residuals for 120 spectra using LBLRTM v9.4+. (d) Mean of the a priori brightness temperature residuals for 120 spectra using LBLRTM v12.1. (e) Mean of the a priori brightness temperature residuals for 120 spectra using LBLRTM v9.4+. The $\mathrm{O}_{3}$ retrieval window is highlighted in red. Note that the RMS due to instrument noise alone in this retrieval window is $0.027 \mathrm{~K}$.

and R-branches like IASI will have more sensitivity to nearsurface water vapor in moist atmospheres than an instrument like AIRS or CrIS, which only measures radiances within the P-branch. Thus including the R-branch in the water vapor retrieval can substantially alter the retrieved $\mathrm{H}_{2} \mathrm{O}$ mixing ratio near the surface. Figure 25 shows the mean and standard deviation of the ratio of the LBLRTM v12.1 retrieved $\mathrm{H}_{2} \mathrm{O}$ profiles that only included the P-branch to those that included both the P- and R-branches as discussed in Sect. 4. Both the mean and variability of the differences is small above $500 \mathrm{hPa}$, but the P-branch-only retrievals show on average $33 \%$ more water vapor than the P- and R-branch retrievals near the surface, with a variability of $\pm 51 \%$. These differences are not necessarily due to inconsistencies in the spectroscopy between the branches, but rather reflect that the regions of the $\mathrm{P}$-branch most sensitive to near-surface water vapor were removed from the retrieval to avoid interferences 

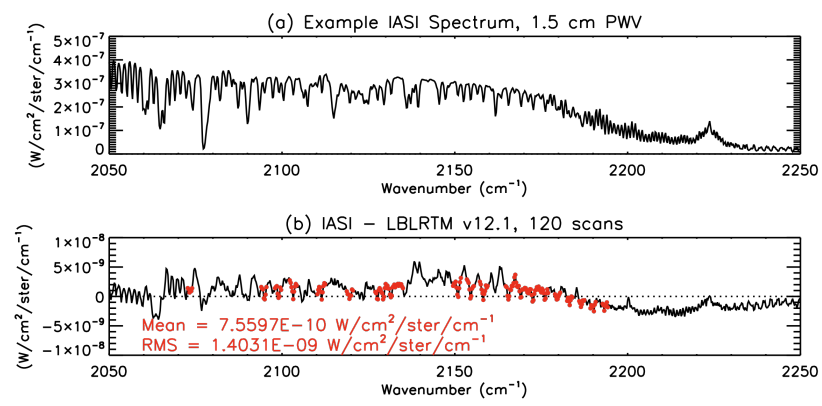

(c) IASI - LBLRTM v9.4+, 120 scans
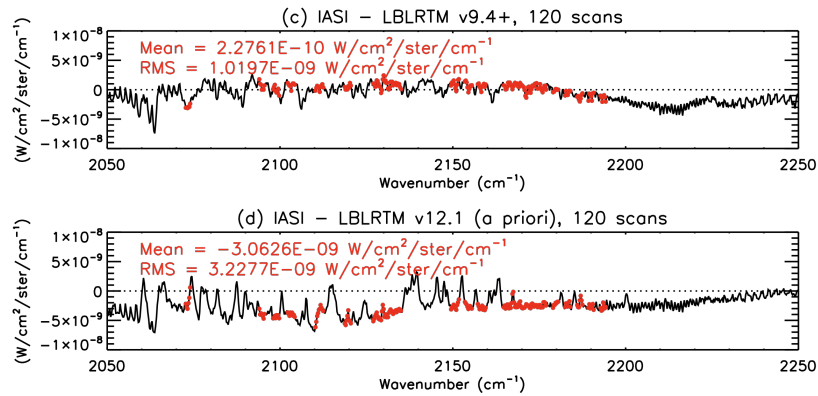

(e) IASI - LBLRTM $v 9.4+$ (o priori), 120 scans

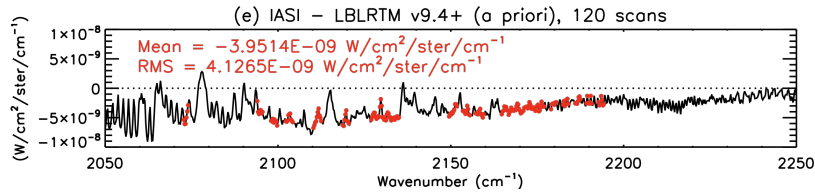

Fig. 27. (a) IASI-observed radiance spectrum in the fundamental vibrational band of CO for an example profile with $1.5 \mathrm{~cm}$ PWV. (b) Mean of the final (a posteriori) radiance residuals for 120 spectra using LBLRTM v12.1. (c) Mean of the final radiance residuals for 120 spectra using LBLRTM v9.4+. (d) Mean of the a priori radiance residuals for 120 spectra using LBLRTM v12.1. (e) Mean of the a priori radiance residuals for 120 spectra using LBLRTM v9.4+. The CO retrieval windows are highlighted in red. Note that the RMS due to instrument noise alone in these windows is $1.8 \times 10^{-10}$ $\mathrm{W} \mathrm{cm}{ }^{-2} \mathrm{ster}^{-1} \mathrm{~cm}$.

from the $\mathrm{CH}_{4} v_{4}$ band (centered near $1306 \mathrm{~cm}^{-1}$ ) and the $\mathrm{N}_{2} \mathrm{O} v_{1}$ band (centered near $1285 \mathrm{~cm}^{-1}$ ).

\section{$5.3 \quad O_{3} v_{3}$ band $\left(950-1150 \mathrm{~cm}^{-1}\right)$}

Figure 26 shows the mean of the final brightness temperature residuals in the $\mathrm{O}_{3} \nu_{3}$ band for the 120 IASI spectra for both LBLRTM v12.1 (Fig. 26b) and v9.4+ (Fig. 26c). The mean a priori residuals for each model are presented in Fig. 26d and e. The $\mathrm{O}_{3}$ retrieval window (see Table 1) is highlighted in red. The final a posteriori residuals show little change between LBLRTM v9.4+ and v12.1: both show positive residuals of about $0.3 \mathrm{~K}$ in the R-branch of the band that have little dependence on PWV. The a priori residuals also show little change between versions. As the $\mathrm{O}_{3}$ spectroscopy in this region was not substantially changed between LBLRTM v9.4+ and v12.1, these small differences are likely due to the improved temperature retrieval in LBLRTM v12.1 (see Sect. 5.1) and/or the changes in the $\mathrm{H}_{2} \mathrm{O}$ and $\mathrm{CO}_{2}$ spec- (a) IASI Scan \#754 A Priori, LBLRTM v12.1
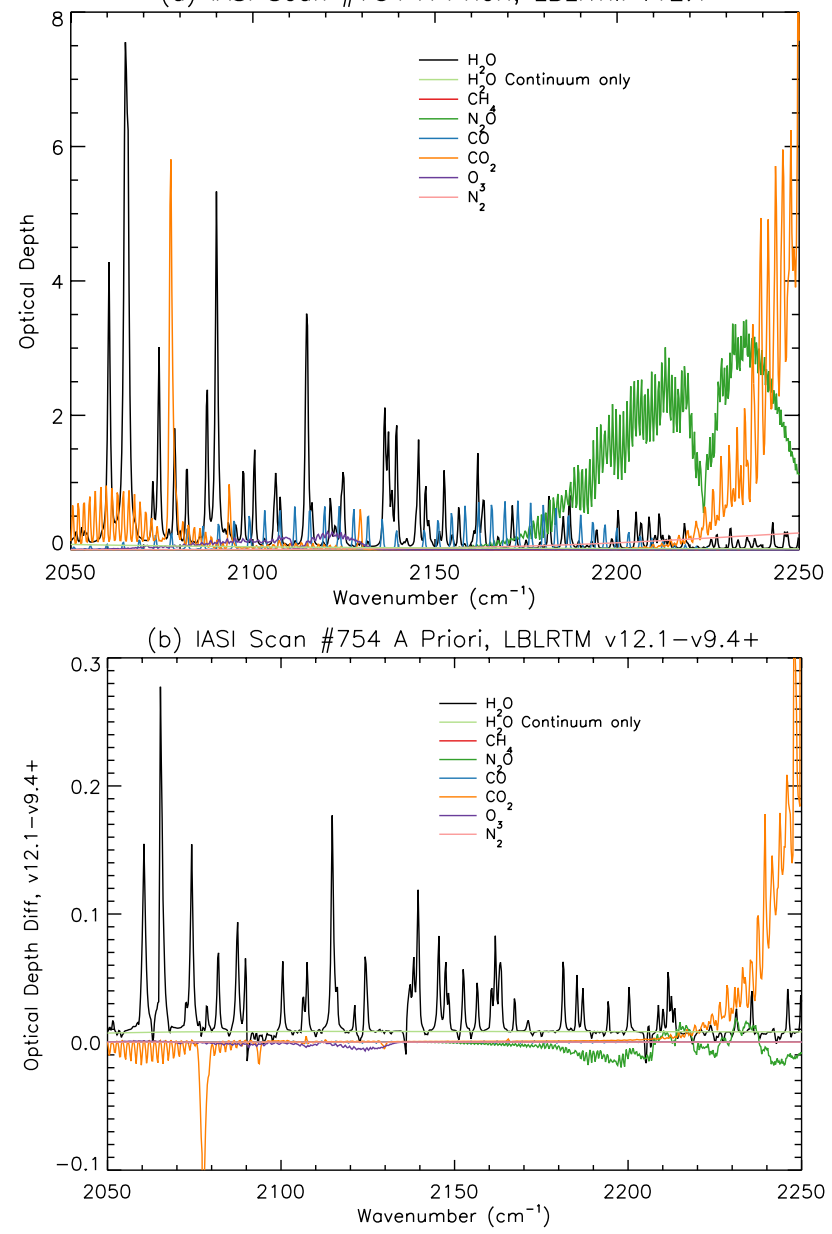

Fig. 28. (a) Convolved optical depth (calculated as the negative of the natural logarithm of the convolved transmittance for LBLRTM runs with a single absorbing gas) for each species near the fundamental vibrational band of CO. (b) Change in convolved optical depth between LBLRTM v12.1 and LBLRTM v9.4+.

troscopy in this region. The retrieved ozone profiles (not shown) also show little change between the two model versions: the mean differences between the profiles are generally less than $3 \%$ at altitudes below the $10 \mathrm{hPa}$ surface.

\subsection{CO fundamental band $\left(2050-2250 \mathrm{~cm}^{-1}\right)$}

Figure 27 shows the mean of the final brightness temperature residuals in the fundamental vibrational band of $\mathrm{CO}$. The $\mathrm{CO}$ retrieval windows (see Table 1) are illustrated with red dots, and the mean and RMS residuals for the $\mathrm{CO}$ windows are printed in red. Based on the RMS of the a priori residuals, one would be tempted to conclude that LBLRTM v12.1 performs better in this region. However, we can see that the final a posteriori residuals between 2060 and $2170 \mathrm{~cm}^{-1}$ have increased in LBLRTM v12.1, both within and outside the $\mathrm{CO}$ windows. As $\mathrm{CO}$ spectroscopy was unchanged between 


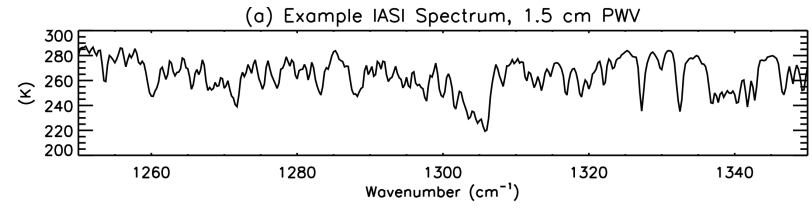

(b) IASI - LBLRTM v12.1, 120 scons

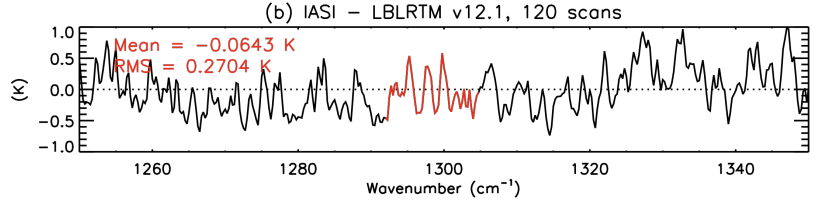

(c) IASI - LBLRTM v9.4+, 120 scans

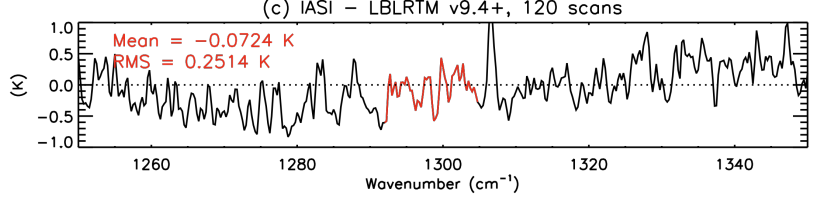

(d) IASI - LBLRTM V12.1 (a priori), 120 scans

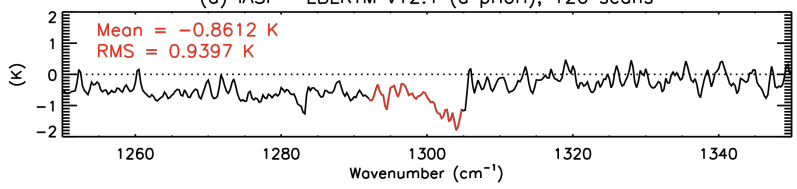

(e) IASI - LBLRTM v9.4+ (a priori), 120 scans

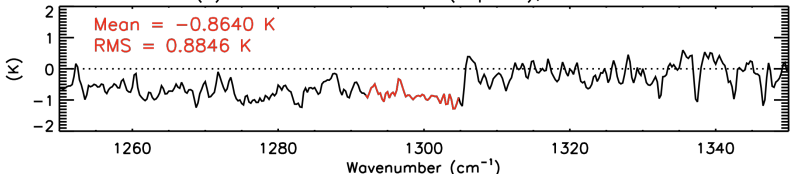

Fig. 29. (a) IASI-observed brightness temperature spectrum in the $v_{4}$ band of $\mathrm{CH}_{4}$ for an example profile with $1.5 \mathrm{~cm}$ PWV. (b) Mean of the final (a posteriori) brightness temperature residuals for 120 spectra using LBLRTM v12.1. (c) Mean of the final brightness temperature residuals for 120 spectra using LBLRTM v9.4+. (d) Mean of the a priori brightness temperature residuals for 120 spectra using LBLRTM v12.1. (e) Mean of the a priori brightness temperature residuals for 120 spectra using LBLRTM v9.4+. The $\mathrm{CH}_{4}$ retrieval window is highlighted in red. Note that the RMS due to instrument noise alone in this retrieval window is $0.016 \mathrm{~K}$.

LBLRTM v9.4+ and v12.1, the differences between the two model versions in this spectral region are primarily due to the changes in water vapor spectroscopy in this region. Figure 28a shows the optical depth from the major absorbers in this region for a profile with $1.5 \mathrm{~cm}$ PWV, while Fig. 28b shows the changes in optical depth between the two versions of LBLRTM. We can see that the optical depth of the $\mathrm{H}_{2} \mathrm{O}$ lines has substantially increased in this region, and that the $\mathrm{H}_{2} \mathrm{O}$ self-continuum was increased in this region in MT_CKD v2.5. However, since the CO windows were selected to avoid strong water lines, the increased positive residuals within the $\mathrm{CO}$ windows are likely due to the increase of the $\mathrm{H}_{2} \mathrm{O}$ self-continuum in MT_CKD v2.5, suggesting the updated self-continuum in this region is inconsistent with the spectroscopy of the $\mathrm{H}_{2} \mathrm{O} v_{2}$ band used to retrieve the water vapor profiles. This change to the continuum was motivated by the need to improve agreement with

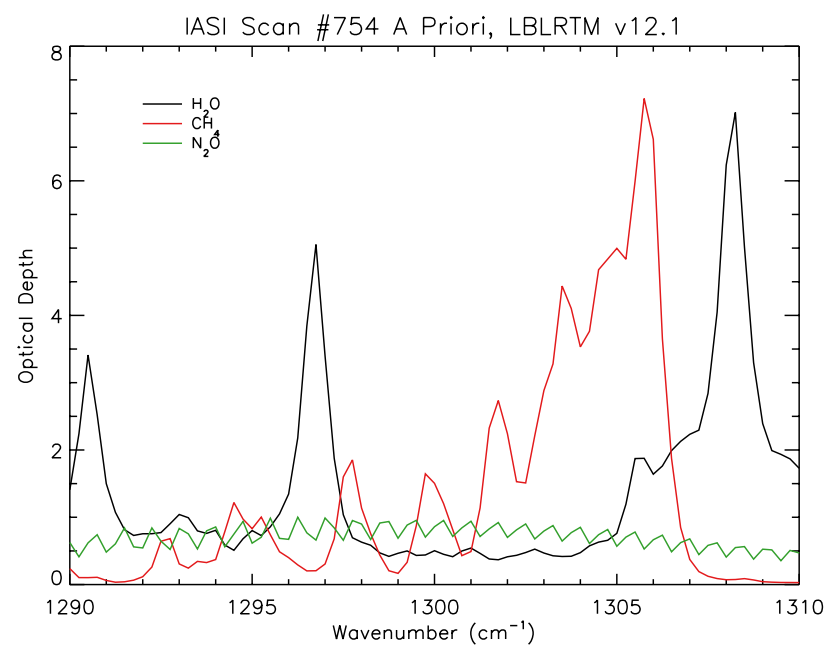

Fig. 30. Convolved optical depth (calculated as the negative of the natural logarithm of the convolved transmittance for LBLRTM runs with a single absorbing gas) of $\mathrm{H}_{2} \mathrm{O}$ (which includes $\mathrm{HDO}$ ), $\mathrm{N}_{2} \mathrm{O}$, and $\mathrm{CH}_{4}$ near the $v_{4}$ band of $\mathrm{CH}_{4}$.

measurements near the $\mathrm{CO}_{2} v_{3}$ band head (see Sect. 5.1), but it clearly has the unintended consequence of degrading the match with observations between 2060 and $2170 \mathrm{~cm}^{-1}$. It also affects the retrieved profiles of $\mathrm{CO}$ (not shown): the differences can be $40 \mathrm{ppb}$ or larger for cases with PWV between 4 and $6 \mathrm{~cm}$. Thus, correcting the MT_CKD $2.5 \mathrm{H}_{2} \mathrm{O}$ selfcontinuum in this spectral region (i.e., removing the scale factors applied to the MT_CKD v1.0 continuum between 2050 and $2200 \mathrm{~cm}^{-1}$; see Mlawer et al., 2012) is critical to the accurate retrieval of $\mathrm{CO}$ concentrations. It is important to note that the recently developed CAVIAR water vapor self-continuum (Ptashnik et al., 2011) is even greater than MT_CKD_2.5 in this region.

\section{$5.5 \mathrm{CH}_{4} v_{4}$ band $\left(1250-1350 \mathrm{~cm}^{-1}\right)$}

Figure 29 shows the mean of the final average brightness temperature residuals in the $\mathrm{CH}_{4} v_{4}$ band for both LBLRTM v12.1 (Fig. 29b) and v9.4+ (Fig. 29c). The mean a priori residuals for each model are presented in Fig. $29 \mathrm{~d}$ and e. The HITRAN 2008 updates to the $\mathrm{CH}_{4}$ line parameters, along with the line mixing calculations of Tran et al. (2006), have substantially changed the shape of the final residuals, leaving three clear residual peaks at about 1295, 1297.5 and $1300 \mathrm{~cm}^{-1}$ in LBLRTM v12.1 that have only a slight dependence on PWV. However, it is not clear if the residuals have substantially improved: the RMS of both the final and a priori residuals is slightly larger, and thus we cannot conclude that the updated $\mathrm{CH}_{4}$ spectroscopy is a clear improvement. Figure 30, which shows the optical depth for $\mathrm{CH}_{4}$, $\mathrm{H}_{2} \mathrm{O}$ (which includes $\mathrm{HDO}$ ), and $\mathrm{N}_{2} \mathrm{O}$ in this spectral region, demonstrates that the three residual peaks in Fig. 29b are associated with $\mathrm{CH}_{4}$ lines, and thus likely reflect errors 
in $\mathrm{CH}_{4}$ spectroscopy. We also examined the impact of including $\mathrm{CH}_{4}$ line coupling on the spectral residuals and retrieved $\mathrm{CH}_{4}$ profiles for our three representative spectra (see Sect. 5.2). The addition of line coupling to HITRAN 2008 changed the mean of the spectral residuals in the $\mathrm{CH}_{4}$ window by less than $0.004 \mathrm{~K}$ and the RMS by less than $0.003 \mathrm{~K}$, suggesting that the addition of $\mathrm{CH}_{4}$ line coupling had little impact on the differences between LBLRTM v12.1 and LBLRTM v9.4+ in the $\mathrm{CH}_{4} v_{4}$ band.

However, the spectroscopic issues in the $\mathrm{CH}_{4} v_{4}$ band will also impact the retrieved $\mathrm{CH}_{4}$ profiles, and so we must evaluate both to evaluate the updated spectroscopy. Retrieval of $\mathrm{CH}_{4}$ from satellite observations is recognized as a difficult problem due to the presence of interfering species (e.g., $\mathrm{H}_{2} \mathrm{O}$, HDO, $\mathrm{N}_{2} \mathrm{O}$; Worden et al., 2012), errors in the $\mathrm{CH}_{4}$ spectroscopy (such as those discussed above), and the fact that, as $\mathrm{CH}_{4}$ is reasonably well-mixed in the troposphere, we are interested in small changes $(\sim 50 \mathrm{ppbv})$ on a relatively large background mixing ratio ( $1800 \mathrm{ppbv})$. Most operational satellite retrievals of $\mathrm{CH}_{4}$ using the $v_{4}$ band show positive biases relative to in situ observations (e.g., Razavi et al., 2009; Wecht et al., 2012), which are corrected for by various methods, such as correcting the $\mathrm{CH}_{4}$ retrieved profile by assuming that deviations of the retrieved $\mathrm{N}_{2} \mathrm{O}$ profile from the a priori are a result of systematic errors that also impact the retrieved $\mathrm{CH}_{4}$ (Razavi et al., 2009; Worden et al., 2012). As the goal of our study is to validate the spectroscopy in LBLRTM, rather than to design an accurate retrieval for $\mathrm{CH}_{4}$, our retrieval approach was fairly simplistic (see Sect. 4). We performed a single-species retrieval and used only a small spectral region in an attempt to avoid interference from $\mathrm{H}_{2} \mathrm{O}$ and $\mathrm{N}_{2} \mathrm{O}$. We recognize that we retrieved unphysically large mixing ratios of $\mathrm{CH}_{4}$ in the free troposphere in both model versions. However, the average retrieved $\mathrm{CH}_{4}$ mixing ratio at altitudes below the $100 \mathrm{hPa}$ surface was reduced by $44 \mathrm{ppbv}$ when the updated $\mathrm{CH}_{4}$ spectroscopy in LBLRTM v12.1 was used, suggesting that the updated spectroscopy might improve operational retrievals of $\mathrm{CH}_{4}$ from satellites by reducing the current positive biases in these retrievals. In fact, our preliminary work with the Tropospheric Emission Spectrometer (TES) retrievals of $\mathrm{CH}_{4}$ (which simultaneously retrieve $\mathrm{N}_{2} \mathrm{O}, \mathrm{HDO}$, and $\mathrm{H}_{2} \mathrm{O}$; see Worden et al., 2012) suggests that the new $\mathrm{CH}_{4}$ spectroscopy in LBLRTM v12.1 reduces the positive bias in TES $\mathrm{CH}_{4}$ retrievals compared with aircraft observations from $+40 \mathrm{ppb}$ to $+23 \mathrm{ppb}$ while generally improving the spectral residuals between 1190 and $1320 \mathrm{~cm}^{-1}$ (Alvarado et al., 2013).

\section{Conclusions}

We have performed an extensive validation of the thermal infrared spectroscopy (between 645 and $2760 \mathrm{~cm}^{-1}$ ) in LBLRTM v12.1 using a global dataset of 120 clear-sky, nighttime spectra measured over the ocean with the IASI in- strument, and have compared the performance of LBLRTM v12.1 with a previous version of LBLRTM (v9.4+) to determine if the spectroscopy in various spectral regions has improved over time.

We find that the $\mathrm{CO}_{2}$ spectroscopy in the $v_{2}$ and $v_{3}$ bands is significantly improved in LBLRTM v12.1 relative to v9.4+. The spectroscopy of the two bands is remarkably consistent in LBLRTM v12.1, as determined both by spectral residuals and by comparing the atmospheric temperature profiles retrieved with each band. The improvement in the spectroscopy in these bands is mainly due to (1) the addition of P- and R-branch line coupling for $\mathrm{CO}_{2}$ based on Lamouroux et al. (2010), (2) the addition of CDSD line positions and intensities (Tashkun et al., 2003; Flaud et al., 2003), and (3) improvements in the $\mathrm{CO}_{2}$ foreign and $\mathrm{H}_{2} \mathrm{O}$ self-continua near the $v_{3}$ band head. Including the $667 \mathrm{~cm}^{-1} \mathrm{Q}$-branch of $\mathrm{CO}_{2}$ in the retrieval of atmospheric temperature substantially improves the a posteriori spectral residuals in this region relative to the results of Shephard et al. (2009), and the remaining average spectral residuals of about $-0.5 \mathrm{~K}$ are consistent with the results of Masiello et al. (2011). Other remaining a posteriori residual features in these bands include a negative residual of $-0.5 \mathrm{~K}$ in the $720 \mathrm{~cm}^{-1} \mathrm{Q}$-branch of $\mathrm{CO}_{2}$, a positive offset of about $0.2 \mathrm{~K}$ between 755 and $770 \mathrm{~cm}^{-1}$, and a small residual feature near the $v_{3}$ band head.

We have also examined the impact of the updated $\mathrm{CO}_{2}$ spectroscopy on the temperature profiles retrieved using the $v_{2}$ band of $\mathrm{CO}_{2}$. The retrieved temperatures with the updated spectroscopy are on average $0.6 \pm 0.8 \mathrm{~K}$ higher at $562 \mathrm{hPa}$, $0.5 \pm 0.4 \mathrm{~K}$ lower in the upper troposphere near $300 \mathrm{hPa}$, $0.8 \pm 0.7 \mathrm{~K}$ higher in the UTLS region between 100 and $200 \mathrm{hPa}, 0.4 \pm 0.4 \mathrm{~K}$ lower between 40 and $100 \mathrm{hPa}$ and $0.3 \pm 0.5 \mathrm{~K}$ lower between 10 and $30 \mathrm{hPa}$. The RMS differences between the a posteriori and a priori temperature profiles are generally lower in v12.1 than in v9.4+. These changes are consistent with the improvements in the spectroscopy between 700 and $750 \mathrm{~cm}^{-1}$, with most of the UTLS and stratospheric improvements likely due to spectroscopic improvements in the region near the $720 \mathrm{~cm}^{-1}$ Q-branch.

The updated $\mathrm{H}_{2} \mathrm{O}$ spectroscopy in LBLRTM v12.1 substantially reduces the RMS of the a posteriori residuals in the P-branch of the $\mathrm{H}_{2} \mathrm{O} v_{2}$ band due to both the improved temperature retrieval and the improved $\mathrm{H}_{2} \mathrm{O}$ spectroscopy in this region. The improvements in the R-branch are more modest and appear to be primarily due to the improved temperature retrievals in LBLRTM v12.1 rather than the improvements in the $\mathrm{H}_{2} \mathrm{O}$ spectroscopy, although the updated spectroscopy has reduced some systematic residual features in the R-branch that were present in the LBLRTM v9.4+ residuals. We find that the use of a fixed ratio of $\mathrm{HDO}$ to $\mathrm{H}_{2} \mathrm{O}$ in LBLRTM may be responsible for a significant fraction of the remaining bias in the P-branch of the $\mathrm{H}_{2} \mathrm{O} \nu_{2}$ band relative to the R-branch. We also find that including the calculated Coudert et al. (2008) line positions and intensities, as in LBLRTM v12.1, is necessary for proper modeling of the 
R-branch of the $\mathrm{H}_{2} \mathrm{O} v_{2}$ band, as excluding the calculated values (as in HITRAN 2008) leads to discontinuities in the residuals within the R-branch.

The updated $\mathrm{H}_{2} \mathrm{O}$ spectroscopy also has significant impacts on the retrieved $\mathrm{H}_{2} \mathrm{O}$ profiles. The retrieved $\mathrm{H}_{2} \mathrm{O}$ with the new spectroscopy is on average $14 \% \pm 8 \%$ lower between 100 and $200 \mathrm{hPa}, 42 \% \pm 58 \%$ higher near $562 \mathrm{hPa}$, and $31 \% \pm 100 \%$ higher near the surface. At altitudes below the $600 \mathrm{hPa}$ surface, LBLRTM v12.1 has a smaller RMS difference between the a posteriori and a priori $\mathrm{H}_{2} \mathrm{O}$ profiles than v9.4+, while the two models have similar RMS values at higher altitudes. These changes are due to a combination of $\mathrm{H}_{2} \mathrm{O}$ spectroscopy changes and the temperature profile changes (themselves caused by $\mathrm{CO}_{2}$ spectroscopy changes). The upper atmospheric changes are consistent with the results of Shephard et al. (2009), who showed that the addition of the Coudert et al. (2008) line positions and intensities to HITRAN 2004 resulted in a $10 \%$ reduction in the upper tropospheric $\mathrm{H}_{2} \mathrm{O}$ mixing ratio. We also find that including the R-branch of the $\mathrm{H}_{2} \mathrm{O} \nu_{2}$ band can provide more information on near-surface $\mathrm{H}_{2} \mathrm{O}$ for moist cases, with the P-branch retrievals showing on average $33 \% \pm 51 \%$ more $\mathrm{H}_{2} \mathrm{O}$ than the $\mathrm{P}$ - and R-branch retrievals near the surface.

We have identified the remaining systematic residuals in the main absorption bands of $\mathrm{O}_{3}, \mathrm{CO}$, and $\mathrm{CH}_{4}$ within the IASI spectral range. Neither the spectroscopy nor the retrievals of $\mathrm{O}_{3}$ have changed significantly between LBLRTM $\mathrm{v} 9.4+$ and v12.1, and thus significant average a posteriori residuals of $+0.3 \mathrm{~K}$ remain in the R-branch of the $\nu_{3}$ band of $\mathrm{O}_{3}$. While the updates to the $\mathrm{H}_{2} \mathrm{O}$ self-continuum in MT_CKD v2.5 have clearly improved the match with observations near the $\mathrm{CO}_{2} \nu_{3}$ band head, these updates have degraded the match with observations in the fundamental band of CO (between 2060 and $2170 \mathrm{~cm}^{-1}$ ) and can create significant errors in the retrieved $\mathrm{CO}$ profile for profiles with high levels of water vapor. An improved version of the MT_CKD self-continuum is needed to preserve the improved $\mathrm{H}_{2} \mathrm{O}$ self-continuum values in the $\mathrm{CO}_{2} \nu_{3}$ band while returning the $\mathrm{H}_{2} \mathrm{O}$ self-continuum in the $2060-2170 \mathrm{~cm}^{-1}$ range to the values used in MT_CKD 2.4. Finally, significant systematic residuals remain in the $v_{4}$ band of $\mathrm{CH}_{4}$, even with the updated spectroscopy, which leads to unphysically large retrieved mixing ratios of $\mathrm{CH}_{4}$ using our rather simple retrieval procedure. However, the average $\mathrm{CH}_{4}$ mixing ratios at altitudes below the $100 \mathrm{hPa}$ surface are reduced by $44 \mathrm{ppbv}$ when LBLRTM v12.1 is used instead of LBLRTM v9.4+, suggesting that this updated $\mathrm{CH}_{4}$ spectroscopy might improve more rigorous retrievals of $\mathrm{CH}_{4}$ from satellite observations, which currently can show positive biases relative to in situ observations. This suggests the need for further work on evaluating the updated $\mathrm{CH}_{4}$ spectroscopy for use in operational $\mathrm{CH}_{4}$ retrievals.

\section{Supplementary material related to this article is available online at: http://www.atmos-chem-phys.net/13/ 6687/2013/acp-13-6687-2013-supplement.pdf.}

Acknowledgements. The authors would like to thank S. A. Clough, who made substantial contributions to several of the spectroscopic improvements evaluated in this work. Without his long history of development and validation of LBLRTM, this study would not have been possible. We thank Marco Matricardi for providing the IASI spectra and ECMWF model profiles used in this analysis. We thank Linda Brown, Robert Gamache, and Jean-Michel Hartmann for providing us with many of the spectroscopic parameters evaluated in this study. We thank Kevin Wecht for his helpful comments. We also thank the two anonymous reviewers, whose careful reading of our manuscript and insightful comments resulted in a stronger paper. This work was partially funded under NASA grants NNH11CD78C and NMO710803 and grant NA10NES4400009 from the NOAA Joint Center on Satellite Data Assimilation. Part of this research was carried out at the Jet Propulsion Laboratory, California Institute of Technology, under a contract with the National Aeronautics and Space Administration.

Edited by: S. Buehler

\section{References}

Alvarado, M. J., Cady-Pereira, K. E., Payne, V. H., Kulawik, S. S., Worden, J. R., and Wecht, K. J.: Evaluation of Recent Spectroscopic Updates and Their Impacts on TES $\mathrm{CH}_{4}$ and $\mathrm{CO}_{2}$ Retrievals, presented at the TES Science Team Meeting, Cambridge, MA, USA, 18-19 March, 2013.

Amato, U., Masiello, G., Serio, C., and Viggiano, M.: The $\sigma$ IASI code for the calculation of infrared atmospheric radiance and its derivatives, Environ. Model. Softw., 17, 651-667, doi:10.1016/S1364-8152(02)00027-0, 2002.

Baranov, Y. I.: The continuum absorption in $\mathrm{H}_{2} \mathrm{O}+\mathrm{N}_{2}$ mixtures in the $2000-3250 \mathrm{~cm}^{-1}$ spectral region at temperatures from 326 to 363 K, J. Quant. Spectrosc. Ra. Transf., 112, 2281-2286, doi:10.1016/j.jqsrt.2011.06.005, 2011.

Baranov, Y. I. and Lafferty, W. J.: The water vapour self- and waternitrogen continuum absorption in the 1000 and $2500 \mathrm{~cm}^{-1}$ atmospheric windows, Philos. Trans. Roy. Soc. A, 370, 2691-2709, doi:10.1098/rsta.2011.0234, 2012.

Bicknell, W. E., Cecca, S. D., and Griffin, M. K.: Search for low absorption regions in the 1.6 and $2.1 \mathrm{~mm}$ atmospheric windows, J. Directed Energy, 2, 151-161, 2006.

Blumstein, D., Tournier, B., Cayla, F. R., Phylpin, T., Fjortoft, R., Buil, C., and Ponce, G.: In-flight performance of the Infrared Atmospheric Sounding Interferometer (IASI) on METOP-A, Proc. SPIE 6684, 66840H, San Diego, CA, USA, 26 August, 2007.

Bowman, K. W., Rodgers, C. D., Sund-Kulawik, S., Worden, J., Sarkissian, E., Osterman, G., Steck, T., Luo, M., Eldering, A., Shephard, M. W., Worden, H., Clough, S. A., Brown, P. D., Rinsland, C. P., Lampel, M., Gunson, M., and Beer, R.: Tropospheric emission spectrometer: Retrieval method 
and error analysis, IEEE T. Geosci. Remote, 44, 1297-1307, doi:10.1109/TGRS.2006.871234, 2006.

Brasseur, G. P., Hauglustaine, D. A., Walters, S., Rasch, R. J., Muller, J., Granier, C., and Tie, X. X.: MOZART, a global chemical transport model for ozone and related chemical tracers. 1. Model description, J. Geophys. Res., 103, 28265-28289, doi:10.1029/98JD02397, 1998

Camy-Peyret, C., Payan, S., Jeseck, P., Té, Y., and Hawat, T.: High resolution balloon-borne spectroscopy within the $\mathrm{O}_{2}$ A-band: observations and radiative transfer modelling, Abstract E4, Proceedings of the International Radiation Symposium, Saint Petersburg, Russia, 24-29 July 2000.

Chalon, G., Cayla, F., and Diebel, D.: IASI: An advanced sounder for operational meteorology, Proceedings of the 52nd Congress of the International Astronautical Federation, Toulouse, France, 1-5 October 2001.

Clough, S. A., Iacono, M. J., and Moncet, J.-L.: Line-by-line calculation of atmospheric fluxes and cooling rates: Application to water vapor, J. Geophys. Res., 97, 15761-15785, 1992.

Clough, S. A., Rinsland, C. P., and Brown, P. D.: Retrieval of tropospheric ozone from simulations of nadir spectral radiances as observed from space, J. Geophys. Res., 100, 16579-16593, 1995.

Clough, S. A., Shephard, M. W., Mlawer, E. J., Delamere, J. S., Iacono, M. J., Cady-Pereira, K., Boukabara, S., and Brown, P. D.: Atmospheric radiative transfer modeling: a summary of the AER codes, Short Communication, J. Quant. Spectrosc. Ra. Transf., 91, 233-244, 2005.

Clough, S. A., Shephard, M. W., Worden, J., Brown, P. D., Worden, H. M., Luo, M., Rodgers, C. D., Rinsland, C. P., Goldman, A., Brown, L., Sund-Kulawik, S., Eldering, A., Lampel, M. C., Osterman, G., Beer, R., Bowman, K., Cady-Pereira, K. E., and Mlawer, E. J.: Forward Model and Jacobians for Tropospheric Emission Spectrometer Retrievals, IEEE Trans. Geosci. Remote Sens., 44, 1308-1323, 2006.

Coudert, L. H., Wagner, G., Birk, M., Baranov, Yu I., Lafferty, W. J., and Flaud, J.-M.: The $\mathrm{H}_{2}^{16} \mathrm{O}$ molecule: Line position and line intensity analyses up to the second triad, J. Mol. Spectrosc., 251, 339, doi:10.1016/j.jms.2008.03.021, 2008.

Delamere, J. S., Clough, S. A., Payne, V. H., Mlawer, E. J., Turner, D. D., and Gamache, R. R.: A far-infrared radiative closure study in the Arctic: Application to water vapor, J. Geophys. Res., 115, D17106, doi:10.1029/2009JD012968, 2010.

Flaud, J-M., Piccolo, C., and Carli, B.: MIPAS_03: an update of the MIPAS.PF2 database, ESA TN-LPM-IFAC-02, 2003.

Forster, P., V. Ramaswamy, P. Artaxo, T. Berntsen, R. Betts, D.W. Fahey, J. Haywood, J. Lean, D.C. Lowe, G. Myhre, J. Nganga, R. Prinn, G. Raga, M. Schulz and R. Van Dorland, 2007: Changes in Atmospheric Constituents and in Radiative Forcing, in: Climate Change 2007: The Physical Science Basis. Contribution of Working Group I to the Fourth Assessment Report of the Intergovernmental Panel on Climate Change, edited by: Solomon, S., Qin, D., Manning, M., Chen, Z., Marquis, M., Averyt, K. B., Tignor, M., and Miller, H. L., Cambridge University Press, Cambridge, United Kingdom and New York, NY, USA, 2007.

Forster, P. M., Fomichev, V. I., Rozanov, E., Cagnazzo, C., Jonsson, A. I., Langematz, U., Fomin, B., Iacono, M. J. , Mayer, B., Mlawer, E., Myhre, G., Portmann, R. W., Akiyoshi, H., Falaleeva, V., Gillett, N., Karpechko, A., Li, J., Lemennais, P., Morgenstern, O., Oberländer, S., Sigmond, M., and Shi- bata, K.: Evaluation of radiation scheme performance within chemistry climate models, J. Geophys. Res., 116, D10302, doi:10.1029/2010JD015361, 2011.

Fulghum, S. F. and Tilleman, M. M.: Interferometric calorimeter for the measurement of water-vapor absorption, J. Opt. Soc. Am. B, 8, 2401-2413, 1991.

Hoke, M. L., Clough, S. A., Lafferty, W. J., and Olson, B. W.: Line coupling in oxygen and carbon dioxide, in: IRS 88: current problems in atmospheric radiation, edited by: Lenoble, J. and Geleyn, J. F., A Deepak, Hampton, VA, 368-371, 1989.

Iacono, M. J., Delamere, J. S., Mlawer, E. J., Shephard, M. W., Clough, S. A., and Collins, W.: Radiative forcing by long-lived greenhouse gases: Calculations with the AER radiative transfer models, J. Geophys. Res., 113, D13103, doi:10.1029/2008JD009944, 2008.

Khalil, M. A. K., Rasmussen, R. A., Culbertson, J. A., Prins, J. M., Grimsrud, E. P., and Shearer, M. J.: Atmospheric perfluorocarbons, Environ. Sci. Technol., 37, 4358-4361, 2003.

Lafferty, W. J., Solodov, A. M., Weber, A., Olson, W. B., and Hartmann, J.-M.: Infrared collision-induced absorption by $\mathrm{N}_{2}$ near 4.3 microns for atmospheric applications: Measurements and emprirical modeling, Appl. Optics, 35, 5911-5917, 1996.

Lamouroux, J., Tran, H., Laraia, A. L., Gamache, R. R., Rothman, L. S., Gordon, I. E., and Hartmann, J.-M.: Updated database plus software for line-mixing in $\mathrm{CO}_{2}$ infrared spectra and their test using laboratory spectra in the $1.5-2.3 \mu \mathrm{m}$ region, J. Quant. Spectrosc. Ra. Transf., 111, 2321, doi:10.1016/j.jqsrt.2010.03.006, 2010.

Masiello, G., Matricardi, M., and Serio, C.: The use of IASI data to identify systematic errors in the ECMWF forecasts of temperature in the upper stratosphere, Atmos. Chem. Phys., 11, 10091021, doi:10.5194/acp-11-1009-2011, 2011.

Matricardi, M.: Technical Note: An assessment of the accuracy of the RTTOV fast radiative transfer model using IASI data, Atmos. Chem. Phys., 9, 6899-6913, doi:10.5194/acp-9-6899-2009, 2009.

Matricardi, M., Chevallier, F., Kelly, G., and Thépaut, J.-N.: An improved general fast radiative transfer model for the assimilation of radiance observations, Q. J. Roy. Meteorol. Soc., 130, 153 173, doi:10.1256/qj.02.181, 2004.

McMillin, L. M., Fleming, H. E., and Hill, M. L.: Atmospheric transmittance of an absorbing gas. 3: A computationally fast and accurate transmittance model for absorbing gases with variable mixing ratios, Appl. Opt., 18, 1600-1606, 1979.

McNally, A. P. and Watts, P. D., A cloud detection algorithm for high-spectral-resolution infrared sounders, Q. J. Roy. Meteorol. Soc., 129, 3411-3423, 2003.

Mlawer, E. J., Taubman, S. J., Brown, P. D., Iacono, M. J., and Clough, S. A.: Radiative transfer for inhomogeneous atmospheres: RRTM, a validated correlated-k model for the longwave, J. Geophys. Res., 102, 16663-16682, 1997.

Mlawer, E. J., Payne, V. H., Moncet, J.-L., Delamere, J. S., Alvarado, M. J., and Tobin, D. D.: Development and recent evaluation of the MT_CKD model of continuum absorption, Philos. T. Roy. Soc., 370, 2520-2556, doi:10.1098/rsta.2011.0295, 2012.

Moncet, J.-L., Uymin, G., Lipton, A. E., and Snell, H. E.: Infrared Radiance Modeling by Optimal Spectral Sampling, J. Atmos. Sci., 65, 3917-3934, 2008 
Nassar, R., Bernath, P. F., Boone, C. D., Gettelman, A., McLeod, S. D., and Rinsland, C. P.: Variability in HDO/H2O abundance ratios in the tropical tropopause layer, J. Geophys. Res., 112, D21305, doi:10.1029/2007JD008417, 2007.

Niro, F., Jucks, K., and Hartmann, J.-M.: Spectral calculations in central and wing regions of $\mathrm{CO}_{2}$ IR bands. IV: Software and database for the computation of atmospheric spectra, J. Quant. Spectrosc. Ra. Transf., 95, 469-481, 2005.

NOAA: U.S. Standard Atmosphere, 1976, NOAA-S/T 76-1562, Washington, DC, USA, 227 pp., 1976.

Oreopoulos, L. and Mlawer, E.: The Continual Intercomparison of Radiation Codes (CIRC): Assessing Anew the Quality of GCM Radiation Algorithms, Bulletin of the American Meteorological Society, 91, 30-310, 2010.

Oreopoulos, L., Mlawer, E., Delamere, J., Shippert, T., Cole, J., Fomin, B., Iacono, M., Jin, Z., Li, J., Manners, J., Räisänen, P., Rose, F., Zhang, Y., Wilson, M. J., and Rossow, W.: The Continual Intercomparison of Radiation Codes: Results from phase I, J. Geophys. Res., 117, D06118, doi:10.1029/2011JD016821, 2012.

Payne, V. H., Noone, D., Dudhia, A., Piccolo, C., and Grainger, R. G.: Global satellite measurements of HDO and implications for understanding the transport of water vapour into the stratosphere, Q. J. Roy. Meteorol. Soc., 133, 1459-1471, 2007.

Payne, V. H., Delamere, J. S., Cady-Pereira, K. E., Gamache, R. R., Moncet, J.-L., Mlawer, E. J., and Clough, S. A.: Air-broadened half-widths of the $22 \mathrm{GHz}$ and $183 \mathrm{GHz}$ water vapor lines, IEEE Trans. Geosci. Remote Sens., 46, 3601-3617, 2008.

Perrin, A., Rinsland, C. P., and Goldman, A.: Spectral parameters for the $v_{6}$ region of $\mathrm{HCOOH}$ and its measurement in the infrared tropospheric spectrum, J. Geophys. Res., 104, 1866118666, doi:10.1029/1999JD900358, 1999.

Ptashnik, I. V., McPheat, R. A., Shine, K. P., Smith, K. M., and Williams R. G.: Water vapor self-continuum absorption in nearinfrared windows derived from laboratory measurements, J. Geophys. Res., 116, D16305, doi:10.1029/2011JD015603, 2011.

Ptashnik, I. V., McPheat, R. A., Shine, K. P., Smith, K. M., and Williams, R. G.: Water vapour foreign-continuum absorption in near-infrared windows from laboratory measurements, Philosophical Transactions of the Royal Society A: Mathematical, Phys. Eng. Sci., 370, 2557-2577, 2012.

Randel, W. J., Boville, B. A., Gille, J. C., Bailey, P. L., Massie, S. T., Kumer, J. B., Mergenthaler, J. L., and Roche, A. E.: Simulation of Stratospheric $\mathrm{N}_{2} \mathrm{O}$ in the NCAR CCM2: Comparison with CLAES Data and Global Budget Analyses, J. Atmos. Sci., 51, 2834-2845, 1994.

Razavi, A., Clerbaux, C., Wespes, C., Clarisse, L., Hurtmans, D., Payan, S., Camy-Peyret, C., and Coheur, P. F.: Characterization of methane retrievals from the IASI space-borne sounder, Atmos. Chem. Phys., 9, 7889-7899, doi:10.5194/acp-9-7889-2009, 2009.

Ridgway, W. L., Moose, R. A., and Cogley, A. C.: Atmospheric transmittance/radiance computer code FASCOD2, Sonicraft Inc., Chicago, Ill, 1982.

Rodgers, C. D.: Inverse Methods for Atmospheric Sounding: Theory and Practice, World Sci., Hackensack, NJ, 2000.

Rodgers, C. D. and Connor, B. J.: Intercomparison of remote sounding instruments, J. Geophys. Res., 108, 4116, doi:10.1029/2002JD002299, 2003.
Rosenkranz, P. W.: Shape of the $5 \mathrm{~mm}$ oxygen band in the atmosphere, IEEE Transactions on Antennas and Propagation, 23, 498-506, 1975.

Rothman, L. S., Barbe, A., Benner, D. C., Brown, L. R., CamyPeyret, C., Carleer, M. R., Chance, K. V., Clerbaux, C., Dana, V., Devi, V. M., Fayt, A., Flaud, J.-M., Gamache, R. R., Goldman, A., Jacquemart, D., Jucks, K. W., Lafferty, W. J., Mandin, J.-Y., Massie, S. T., Nemtchinov, V, Newnham, D. A., Perrin, A., Rinsland, C. P., Schroeder, J., Smith, K. M., Smith, M. A. H., Tang, K., Toth, R. A., Vander Auwera, J., Varanasi, P., and Yoshino, K.: The HITRAN Molecular Spectroscopic Database: Edition of 2000 Including Updates through 2001, J. Quant. Spectrosc. Ra. Transf.r, 82, 5-44, 2003.

Rothman, L. S., Jacquemart, D., Barbe, A., Benner, D. C., Birk, M., Brown, L. R., Carleer, M. R., Chackerian, C., Jr., Chance, K., Coudert, L. H., Dana, V., Devi, V. M., Flaud, J.-M., Gamache, R. R., Goldman, A., Hartmann, J.-M., Jucks, K. W., Maki, A. G., Mandin, J.-Y., Massie, S. T., Orphal, J., Perrin, A., Rinsland, C. P., Smith, M. A. H., Tennyson, J., Tolchenov, R. N., Toth, R. A., Vander Auwera, J., Varanasi, P., and Wagner, G.: The HITRAN 2004 molecular spectroscopic database, J. Quant. Spectrosc. Ra. Transf., 96, 139-204, 2005.

Rothman, L. S., Gordon, I. E., Barbe, A., Benner, D. C., Bernath, P. F., Birk, M., Boudon, V., Brown, L. R., Campargue, A., Champion, J.-P., Chance, K., Coudert, L. H., Dana, V., Devi, V. M., Fally, S., Flaud, J.-M., Gamache, R. R., Goldman, A., Jacquemart, D., Kleiner, I., Lacome, N., Lafferty, W. J., Mandin, J.Y., Massie, S. T., Mikhailenko, S. N., Miller, C. E., MoazzenAhmadi, N., Naumenko, O. V., Nikitin, A. V., Orphal, J., Perevalov, V. I., Perrin, A., Predoi-Cross, A., Rinsland, C. P., Rotger, M., Šimečková, M., Smith, M. A. H., Sung, K., Tashkun, S. A., Tennyson, J., Toth, R. A., Vandaele, A. C., and Vander Auwera, J: The HITRAN 2008 molecular spectroscopic database, J. Quant. Spectrosc. Ra. Transf., 110, 533-572, 2009.

Shephard, M. W., Clough, S. A., Delamere, J., Tobin, D. C., Turner, D. D., Revercomb, H. E., Knuteson, R., and Beer, R.: Validation of $\mathrm{CO}_{2}$ line parameters used in temperature retrievals, in: Fourier Transform Spectroscopy, edited by: Sawchuk, A., Vol. 84 of OSA Trends in Optics and Photonics, Optical Society of America, Quebec City, Canada, 3 February 2003.

Shephard, M. W., Clough, S. A., Payne, V. H., Smith, W. L., Kireev, S., and Cady-Pereira, K. E.: Performance of the line-by-line radiative transfer model (LBLRTM) for temperature and species retrievals: IASI case studies from JAIVEx, Atmos. Chem. Phys., 9, 7397-7417, doi:10.5194/acp-9-7397-2009, 2009.

Smith, W. L., Feltz, W. F., Knuteson, R. O., Revercomb, H. E., Woolf, H. M., and Howell, H. B.: The Retrieval of Planetary Boundary Layer Structure Using Ground-Based Infrared Spectral Radiance Measurements, J. Atmos. Ocean. Tech., 16, 323333, 1999.

Strow, L. L., Tobin, D. C., and Hannon, S. E.: A compilation of firstorder line-mixing coefficients for $\mathrm{CO}_{2}$ Q-branches, J. Quant. Spectrosc. Ra. Transf., 52, 281-294, 1994.

Tashkun, S. A., Perevalov, V. I., Teffo, J. L., Rothman, L. S., and Tyuterev, V. G.: Global fitting of $\mathrm{CO}_{2}$ vibration-rotation line positions using the effective Hamiltonian approach, J. Quant. Spectrosc. Ra. Transf., 60, 785-801, 1998.

Tashkun, S. A., Perevalov, V. I., Teffo, J. L., Bykov, A. D., and Lavrentieva, N. N.: CDSD-296, the carbon dioxide spectroscopic 
databank: version for atmospheric applications, 14th International Symposium on High Resolution Molecular Spectroscopy, Krasnoyarsk, Russia, 6-11 July 2003.

Thibault, F., Menoux, V., Le Doucen, R., Rosenman, L., Hartmann, J.-M., and Boulet, Ch.: Infrared collision-induced absorption by $\mathrm{O}_{2}$ near 6.4 microns for atmospheric applications: measurements and emprirical modeling, Appl. Optics, 35, 5911-5917, 1996.

Tjemkes, S. A., Patterson, T., Rizzi, R., Shephard, M. W., Clough, S. A., Matricardi, M., Haigh, J. D., Höpfner, M., Payan, S., Trotsenko, A., Scott, N., Rayer, P., Taylor, J. P., Clerbaux, C., Strow, L. L., DeSouza-Machado, S., Tobin, D., and Knuteson, R.: The ISSWG line-by-line inter-comparison experiment, J. Quant. Spectrosc. Ra. Transf., 77, 433-453, dpo:10.1016/S00224073(02)00174-7, 2003.

Tobin, D. C., Revercomb, H. E., Knuteson, R. O., Lesht, B. M., Strow, L. L. Hannon, S. E., Feltz, W. F., Moy, L. A., Fetzer, E. J., and Cress, T. S.: Atmospheric Radiation Measurement site atmospheric state best estimates for Atmospheric Infrared Sounder temperature and water vapor retrieval validation, J. Geophys. Res., 111, D09S14, doi:10.1029/2005JD006103, 2006.

Tran, H., Flaud, J.-M., Gabard, T., Hase, F., Von Clarmann, T., Camy-Peyret, C., Payan, S., and Hartmann, J.-M.: Model, Software and database for line-mixing effects in the $v_{3}$ and $v_{4}$ bands of $\mathrm{CH}_{4}$ and tests using laboratory and planetary measurements. I. $\mathrm{N}_{2}$ (and air) broadening and the Earth atmosphere, J. Quant. Spectrosc. Ra. Transf., 101, 284-305, 2006.

van Delst, P. F. W. and Wu, X.: A high resolution infrared sea surface emissivity database for satellite applications, Technical Proceedings of The Eleventh International ATOVS Study Conference, Budapest, Hungary, 20-26 September 2000, 407-411, 2000 .
Wagner, G., Birk, M., Schreier, F., and Flaud, J. M.: Spectroscopic database for ozone in the fundamental spectral regions. J. Geophys. Res., 107, 4626, doi:10:1029/2001JD000818, 2002.

Wecht, K. J., Jacob, D. J., Wofsy, S. C., Kort, E. A., Worden, J. R., Kulawik, S. S., Henze, D. K., Kopacz, M., and Payne, V. H.: Validation of TES methane with HIPPO aircraft observations: implications for inverse modeling of methane sources, Atmos. Chem. Phys., 12, 1823-1832, doi:10.5194/acp-12-1823-2012, 2012.

Worden, J., Bowman, K., Noone, D., Beer, R., Clough, S., Eldering, A., Fisher, B., Goldman, A., Gunson, M., Herman, R., Kulawik, S., Lampel, M., Luo, M., Osterman, G., Rinsland, C., Rodgers, C., Sander, S., Shephard, M., and Worden, H.: Tropospheric Emission Spectrometer observations of the tropospheric $\mathrm{HDO} / \mathrm{H}_{2} \mathrm{O}$ ratio: Estimation approach and characterization, 25 August, J. Geophys. Res., 111, D16309, doi:10.1029/2005JD006606, 2006.

Worden, J., Noone, D., Bowman, K., and TES science team and data contributors: Importance of rain evaporation and continental convection in the tropical water cycle, Nature, 445, 528-532, doi:10.1038/nature05508, 2007.

Worden, J., Kulawik, S., Frankenberg, C., Payne, V., Bowman, K., Cady-Peirara, K., Wecht, K., Lee, J.-E., and Noone, D.: Profiles of $\mathrm{CH}_{4}, \mathrm{HDO}, \mathrm{H}_{2} \mathrm{O}$, and $\mathrm{N}_{2} \mathrm{O}$ with improved lower tropospheric vertical resolution from Aura TES radiances, Atmos. Meas. Tech., 5, 397-411, doi:10.5194/amt-5-397-2012, 2012.

$\mathrm{Wu}, \mathrm{X}$. and Smith, W. L.: Emissivity of rough sea surface for 8 $13 \mu \mathrm{m}$ : modeling and verification, Appl. Optics, 36, 2609-2619, 1997. 